\title{
WestVirginiaUniversity
}

THE RESEARCH REPOSITORY @ WVU

Graduate Theses, Dissertations, and Problem Reports

2001

\section{Comparison study of the savings between a single and a double step toll systems}

Juan Arturo Kuthy-Saenger

West Virginia University

Follow this and additional works at: https://researchrepository.wvu.edu/etd

\section{Recommended Citation}

Kuthy-Saenger, Juan Arturo, "Comparison study of the savings between a single and a double step toll systems" (2001). Graduate Theses, Dissertations, and Problem Reports. 1121.

https://researchrepository.wvu.edu/etd/1121

This Thesis is protected by copyright and/or related rights. It has been brought to you by the The Research Repository @ WVU with permission from the rights-holder(s). You are free to use this Thesis in any way that is permitted by the copyright and related rights legislation that applies to your use. For other uses you must obtain permission from the rights-holder(s) directly, unless additional rights are indicated by a Creative Commons license in the record and/ or on the work itself. This Thesis has been accepted for inclusion in WVU Graduate Theses, Dissertations, and Problem Reports collection by an authorized administrator of The Research Repository @ WVU. For more information, please contact researchrepository@mail.wvu.edu. 


\title{
COMPARISON STUDY OF THE SAVINGS BETWEEN A SINGLE AND A DOUBLE STEP TOLL SYSTEMS
}

\author{
Juan Arturo Kuthy-Saenger
}

A Thesis Submitted to the College of Engineering and Mineral Resources at West Virginia University in partial fulfillment of the requirements for the degree of
Master of Science
In
Civil Engineering

\author{
David Martinelli, Ph.D., Chair \\ Lloyd James French, Ph.D. \\ John Zaniewski, Ph.D.
}

Department of Civil and Environmental Engineering

\author{
Morgantown, West Virginia
}

2000

Keywords: Congestion Pricing, Tolling Systems, Transportation Economics, Variable Step Tolls, Electronic Toll Collection. 


\section{ABSTRACT \\ Comparison Study of the Savings between a Single and Double Step Toll Systems. Juan Arturo Kuthy -Saenger}

Solving the problem of highway congestion requires solutions that go beyond the capacity expansion of the roadway and towards effective capacity expansion though innovative operations of facilities. One such innovation is the implementation of congestion tolls in order to set volume levels at economically optimal levels. Transportation researches, for some time, have known the potential of congestion tolls as one solution to the congestion problem, and we are now seeing several cases of facilities operating under a congestion toll. However, essentially all of these cases operate under a single toll, i.e. the toll is fixed and does not change with volume level or any other operating condition. It is hypothesized that a variable toll could yield more efficient use of facilities, thus less congestion.

This research explores the efficiency gains associated with expansion of the congestion toll concept to include variable tolls. This is done first though a theoretical construct that formulates a quantity representing the economic gain associated with a variable toll scheme. A model that relates this economic gain to demand-side variables, supply-side variables, and exogenous variables is developed. The model is then used to conduct experiments yielding the economic gains with respect to these variables. Results of the experiments provide insight as to what conditions variable tolls would be feasible and what conditions they would likely not be feasible. 


\section{AKNOWLEDGMENTS}

I want to give my sincere thanks and appreciation to all the professors and staff of the Department of Civil and Environmental Engineering at West Virginia University, especially to Dr. David Martinelli who directs me on this research work.

This research work certainly was and effort that I especially dedicate to my wife Martha Patricia and my daughter Martha Sofia. Thanks to be always with me with your love and support.

To my parents and family. With deep love. 


\section{TABLE OF CONTENTS}

PAGE

ACKNOWLEDGEMENTS ................................................................................

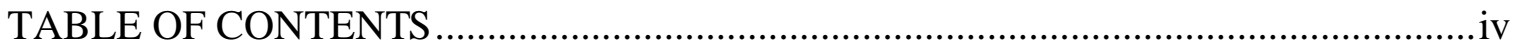

LIST OF TABLES ......................................................................................... vii

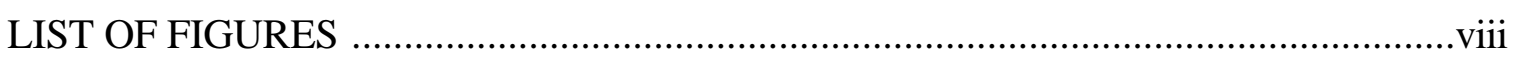

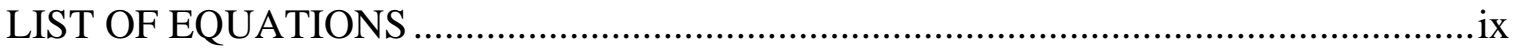

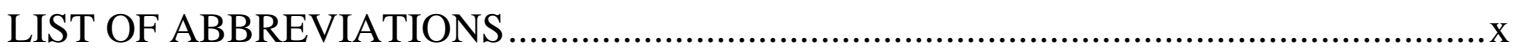

\section{Chapter}

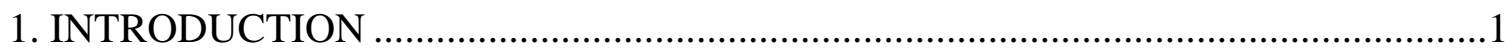

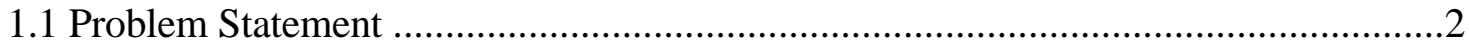

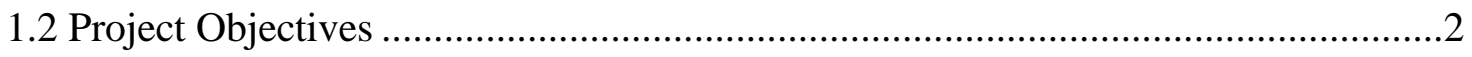

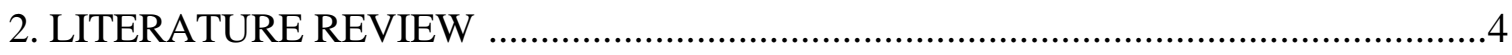

2.1 Congestion Pricing Fundamentals ...............................................................4

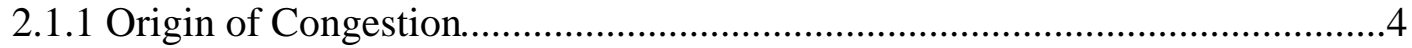

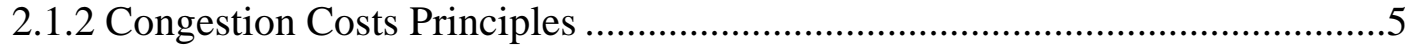

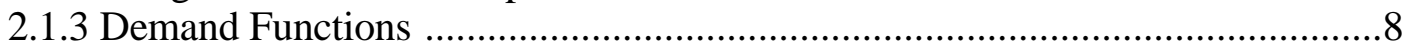

2.1.4 Considerations for the implementation of Congestion Pricing .......................9

2.1.5 Technology for Congestion Pricing ..................................................... 10

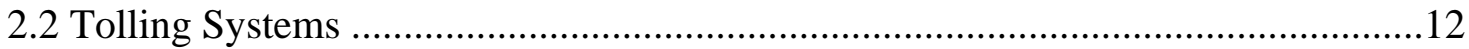

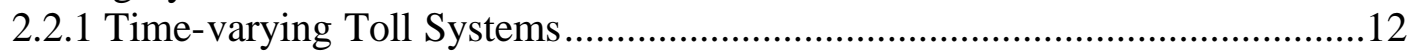

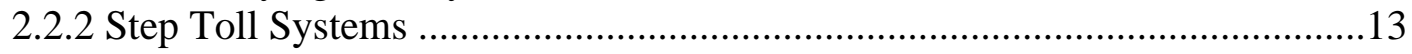

2.3 Other Traffic Congestion Relief Alternatives .....................................................14

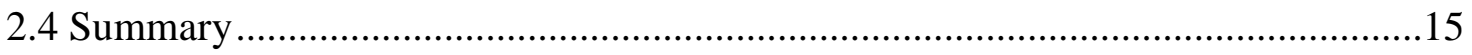


3.1 Introduction

3.2 Single Step and Double Step Toll Models ......................................................17

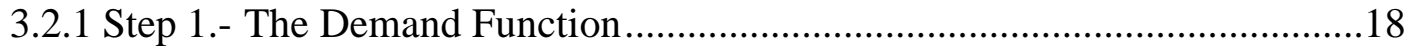

3.2.2 Step 2.- Short Run Average Variable Cost ..................................................19

3.2.3 Step 3.- Short Run Marginal Cost ................................................................22

3.2.4 Step 4.- Single Step Toll and Calculations of Low Toll Function..................23

3.2.5 Step 5.- Savings from Imposing the Single Toll ........................................24

3.2.6 Step 6.- Double Step Toll and Calculations of High Toll Function................25

3.2.7 Step 7.- Savings from Imposing the Double Step Toll .................................26

3.2.8 Step 8.- Comparison of the Single Step Toll Savings and Double Step Toll Savings using Low Toll Function................................................26

3.3 Summary .30

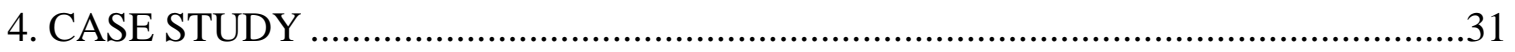

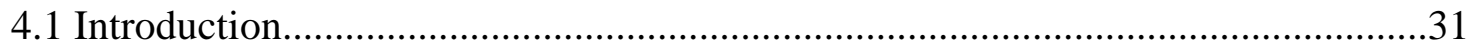

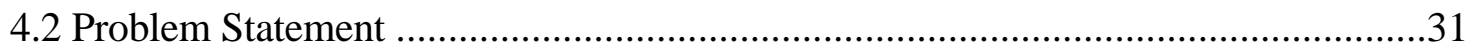

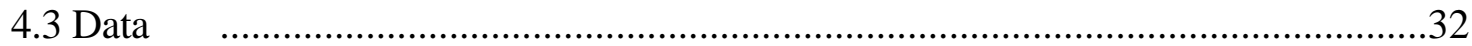

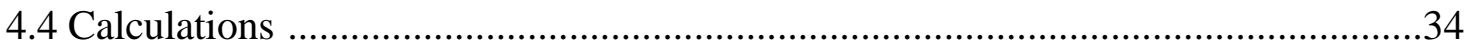

4.4.1 Single Step Toll and Calculation of the Low Toll Function .........................34

4.4.2 Savings from the Single Step Toll System .................................................34

4.4.3 Double Step Toll and Calculations of the High Toll Function …...................35

4.4.4 Savings from the Double Step Toll System.................................................35

4.4.5 Comparison of the Savings between a Single and a Double Step Toll

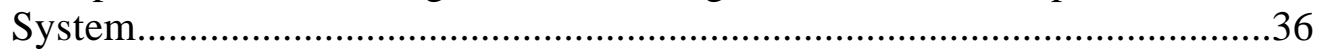

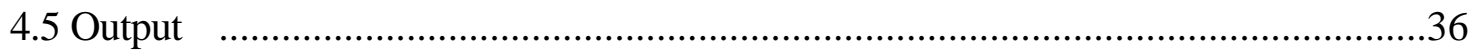

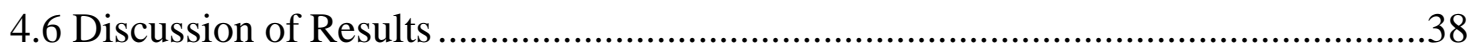

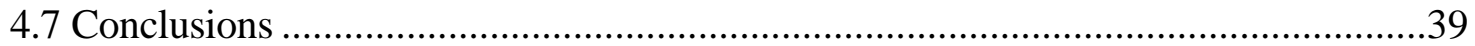

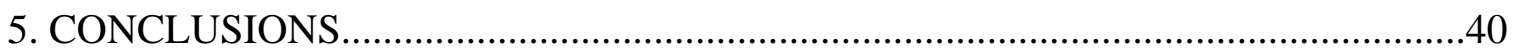

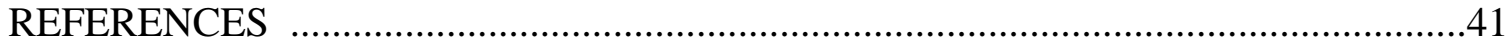


APPENDIX A.- Calculation of the Demand Curve using OLS

APPENDIX B.- Value of Travel Time and Fixed Cost ..............................................46

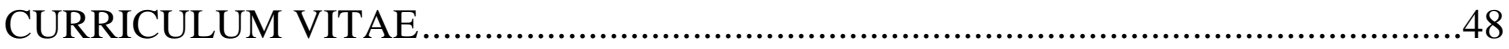




\section{LIST OF TABLES}

4.1 Baseline Data used in the experiments

4.2 Flow rate or Volumes for each experiment

4.3 Short run average variable costs General Equations

4.4 Short run marginal cost General Equations

4.5 Single Step Toll General Equations

4.6 Low Toll Function General Equations

4.7 Single-step Savings General Equations

4.8 Double-step Toll General Equations

4.9 High Toll Function General Equations

4.10 Double-step Savings General Equations

4.11 Single versus Double-step Savings General Equations

4.12 Savings, Queue Removal and Tolls 


\section{LIST OF FIGURES}

2.1 Derivation of the Speed-Flow Curve

2.2 Derivation of the Cost-Flow Relationship

2.3 Optimal Congestion Toll and Welfare Loss

2.4 Electronic Toll Collection System

2.5 Time-Varying Toll System

2.6 Step Toll System

3.1 Shifts in Demand Functions

3.2 Roadway Performance Function

3.3 Cost of an extra user on the facility

3.4 Single and Double Step Toll System Savings and Functions

3.5 Comparison of the Savings between a Single and Double Step Toll Systems 


\section{LIST OF EQUATIONS}

Short Run Total Cost $\quad 2.1$

Short Run Average Total Cost $\quad 2.2$

General Equation of the Short Run Average Variable Cost 2.3

Derivation of the Short Run Marginal Cost Equation $\quad 2.4$

General Equation of the Short Run Marginal Cost 2.5

Demand Function $\quad 2.6$

Marginal Benefit Function $\quad 2.7$

General Equation of the Savings from a Single Step Toll 3.1

General Equation of the Savings from a Double Step Toll 3.2

Demand Low Function $\quad 3.3$

Demand High Function $\quad 3.4$

Marginal Benefits Low Function $\quad 3.5$

Marginal Benefits High Function $\quad 3.6$

Estimation of Travel Time $\quad 3.7$

Short Run Average Variable Cost Equation $\quad 3.8$

Derivation of the Short Run Marginal Cost 3.9

Short Run marginal Cost Equation $\quad 3.10$

Simplified Short Run Marginal Cost Equation $\quad 3.11$

Derivation of the Toll Low Equation $\quad 3.12$

Toll Low Equation $\quad 3.13$

Derivation of the Low Toll Function Equation $\quad 3.14$

Low Toll Function General Equation $\quad 3.15$

Derivation of the Savings from the Single Step Toll System Equation 3.16

Savings from the Single Step Toll System $\quad 3.17$

Derivation of the High Toll General Equation $\quad 3.18$

High Toll General Equation $\quad 3.19$

Derivation of the High Toll Function Equation $\quad 3.20$

High Toll Function Equation $\quad 3.21$

Derivation of the Savings from the Double Step Toll system Equation 3.22

Savings from the Double Step Toll System 3.23

Derivation of the Savings from the Single Vs Double Step Toll System Equation 3.24

Savings from the Single versus Double Step Toll System Equation 3.25

Savings from the n-1 Step Toll System Equation $\quad 3.26$

Function Fn-1 Equation $\quad 3.27$

Savings from the Multiple Step Toll System Equation 3.28 


\section{LIST OF ABBREVIATIONS}

$\begin{array}{ll}\text { SRTC } & \text { Short Run Total Cost } \\ \text { SRVC } & \text { Short Run Variable Cost } \\ \text { sravc } & \text { Short run average variable cost } \\ \text { srmc } & \text { Short run marginal cost } \\ \text { sratc } & \text { Short run average total cost } \\ \text { ETC } & \text { Electronic Toll Collection Systems } \\ \text { AVI } & \text { Automatic Vehicle Identification } \\ \text { HOV } & \text { High Occupancy Vehicle } \\ \text { SOV } & \text { Single Occupancy Vehicle } \\ \text { ATIS } & \text { Automatic Traveler Information Systems } \\ \text { TDM } & \text { Transportation Demand Management } \\ \text { LD } & \text { Low Demand } \\ \text { HD } & \text { High Demand } \\ \text { LT } & \text { Low Toll Function } \\ \text { HT } & \text { High Toll Function } \\ S_{S S} & \text { Savings Single Step } \\ S_{D S} & \text { Savings Double Step } \\ \text { S }_{S v s D} & \text { Savings Single versus Double Step } \\ \tau & \text { Vehicle Fixed Costs } \\ \delta & \text { Speed Reduction Parameter } \\ v & \text { Travel Time Value } \\ \text { V } & \text { Speed } \\ q & \text { Volume } \\ \alpha & \text { Constant Demand Parameter } \\ \beta & \text { Constant Demand Parameter }\end{array}$




\section{Chapter 1. INTRODUCTION}

Through the years, transportation systems have been one of the most important ways to support economic and social development around the world. Open market economies are making possible an ideal world of "no barriers" in which the transportation systems are certainly one of the basic pillars to sustain them.

Transportation systems are in constant development. New technologies and materials produce faster, more reliable, and affordable ways of passenger travel and freight movements. The newest airplanes can travel longer distances and carry more passengers and cargo; the latest railroad technology has increased cargo capacity by three times over twenty years ago. Similar gains have occurred in the motor carrier and maritime modes. Commuting travel is also in a constant growth. Today, people travel twice as much as they did twenty years ago. These developments in transportation systems respond to a world population increase, and their subsequent growing needs. The growth in transportation has many positive outcomes such as economic and social development, but they also have negative effects. The overwhelming negative factor is increased congestion and pollution.

Congestion is a phenomenon that prevails in all the modes of transportation. Categories of congestion include: airplane delays caused by congestion in airports or in the sky, railroad delays caused by congestion on the rail tracks, and the excessive weekday commuter traffic. Congestion mitigation is a question facing researchers and practitioners at all levels. Innovations are being developed for mitigating congestion for all modes. For example, in air transportation, professionals are trying to improve control systems and expand airports. The most obvious approach to address highway congestion is through facility expansion measures such as additional lanes or links in the highway network. However, such methods are costly in terms of time and capital and may even be prohibitively expensive due to environmental regulations and/or land use restrictions. Therefore, alternatives to physical capacity expansion are being explored.

Transportation Demand Management (TDM) are relatively low-cost methods of increasing the effective capacity of a highway network, including: the improvement and promotion of urban transit systems, the promotion of carpooling and HOV (High Occupancy Vehicles), the encouragement of telecommuting and variable working hours, and the use of new technologies such as ITS (Intelligent Transportation systems). One promising, but somewhat controversial approach to congestion mitigation, is the use of congestion pricing schemes.

The definition of congestion pricing refers to charging the user a price that represents the cost users generate in traveling on a segment of highway during congested periods. There are different congestion price mechanisms such as parking fees, daily licenses to enter certain zones at a certain time or day, and tolls imposed on users.

Although highway tolling systems have been in existence in one form or another for decades, congestion tolls on highways are extremely rare. Highway tolls originated as a fee that private road owners charged for access, like the famous old "Turnpikes". Today, some states 
have Turnpikes and toll roads that usually carry less traffic than the non-toll roads and the travel times are shorter.

There are many countries in the world, such as Singapore and Canada, which are using congestion pricing in the form of tolling around urban areas to reduce congestion with very good results. In order to relieve some of the congestion on highways, a toll may be charged as a measure to divert some people off of a congested facility or to switch users from peak periods to off-peak periods.

The most common way of imposing a toll is by charging a single daily or hourly fee to the users of the facility, and to impose this charge according to the prevailing level of congestion. The idea of charging a single fee is desirable because it easier to implement for both users and operators. Nevertheless, this system is not the most accurate or closest indicator to the "real" costs that users impose. If implementations costs are ignored it is probable that some timevarying toll may be more economically efficient.

Therefore, there is likely a pricing scheme between a single toll and time-varying toll that is more efficient than the single toll and more closely resembles to the time- varying toll. Once implementation costs are considered, this is the concept of the step toll system. The approach calls for charging users two or more different tolls during the day according to variations in demand in order to make the toll better-resemble a time-varying system.

\subsection{Problem Statement}

Solving the problem of highway congestion requires solutions that go beyond the capacity expansion of the roadway and towards effective capacity expansion though innovative operations of facilities. One such innovation is the implementation of congestion tolls in order to set volume levels at economically optimal levels. Transportation researches, for some time, have known the potential of congestion tolls as one solution to the congestion problem, and we are now seeing several cases of facilities operating under a congestion toll. However, essentially all of these cases operate under a single toll, i.e. the toll is fixed and does not change with volume level or any other operating condition. It is hypothesized that a variable toll could yield more efficient use of facilities, thus less congestion.

The literature is void of studies comparing but none of the literature discusses the amount of economic savings that the step toll system represents with that of the single step system. This is unfortunate, because, it is important to understand the amount of savings that one system generates over the other.

\subsection{Project Objectives}

The objectives of the project are:

- To review the principles of the marginal cost pricing and how tolling systems can be represented in an market framework. 
- To document the principles of the single and double-step tolling systems.

- To establish a working definition of the economic savings of the single and double-step toll systems over conventional pricing schemes

- To develop a model to represent the parameters of single and double-step toll systems under different scenarios and obtain the economical savings from each system. Savings can be a good parameter to make a decision in terms of implementing a single step toll system or a double step toll system.

- To demonstrate the use of the model developed through an experiment involving several case studies where the most relevant parameters are varied.

The successful completion of these objectives could ultimately result in a reliable and efficient economic evaluation tool. This is relevant since decision makers require reliable estimates of the costs of implementation and operation.

In Chapter 2, a literature review is conducted on the topics of traffic congestion pricing, time-varying, single and multiple-step tolling systems. In Chapter 3, an explanation of the methodology of the model proposed to analyze the amount of economic savings between single and double-step toll systems is discussed. Chapter 4 presents an experiment using the model that compares the economic efficiencies of single and step tolls under different facilities and operating conditions. Finally, Chapter 5 discusses the results and recommendations about the single and double-step tolling systems that can be extracted from the experiment. 


\section{Chapter 2. LITERATURE REVIEW}

The review of the literature in this research is basic to understanding concepts related to the economic efficiency of congestion pricing and toll systems. Literature in the areas of congestion pricing fundamentals, principles of tolls, application and evaluation of the tolling systems are included in this review. The objective of this literature review is to achieve a thorough understanding of the issues relating to existing congestion pricing mechanisms and tolling systems. It also serves to validate the thesis problem statement and objectives by identifying the voids in the state of the art and practice.

\subsection{Congestion Pricing Fundamentals}

For many years roadway pricing has been of interest to economists and engineers. Ellet in 1840 and Dupuit in 1849 addressed the issues of pricing and investment of transport facilities. Later, in the 1920's, Pigou and Knight focused once more on the idea of road pricing but as a financing agent rather than for congestion mitigation. Over the years, as congestion problems became more widely spread, the interest in road pricing as a measure to reduce congestion increased.

2.1.1 Origin of Congestion. Traffic flow theory is the basis for understanding the origin of congestion. The relationship between speed and the number of vehicles per lane-mile or "density" is the starting point for deriving road congestion from uninterrupted flow. This is a fundamental relationship of road traffic that Haight suggested in his research. Figure 2.1a, shows that as the density of vehicles increases, the speed at which they travel decreases.

It is possible to use the speed-density diagram to derive the speed-flow diagram based on the relationship Flow $=$ Speed $*$ Density. For example, the flow of vehicles going at a given speed is indicated by the area of the appropriate rectangle under the speed-density graph. We observe this phenomenon in Part b of Fig. 2.1. The upper portion of the curve shows that, as flow increases, the speed decreases until maximum flow is achieved at what is called "critical density". It is impossible to increase flow beyond this point. Attempts to increase flow result in increased density and reduced flow. According to the diagram, the lower portion of the speedflow curve represents this phenomenon

2.1.2 Congestion Costs Principles. The relationship between speed and density is the starting point for deriving the relationship between road congestion costs and usage for uninterrupted flow. The speed-flow curve is important not only for engineering purposes, but also for economic analysis that is based on the relationship between cost per user and traffic flow. Specifically, it is important to know not only the vehicle operating costs, but also the costs associated with congestion, such as the increase in trip times relative to the value that travelers place on their time. 
(a)

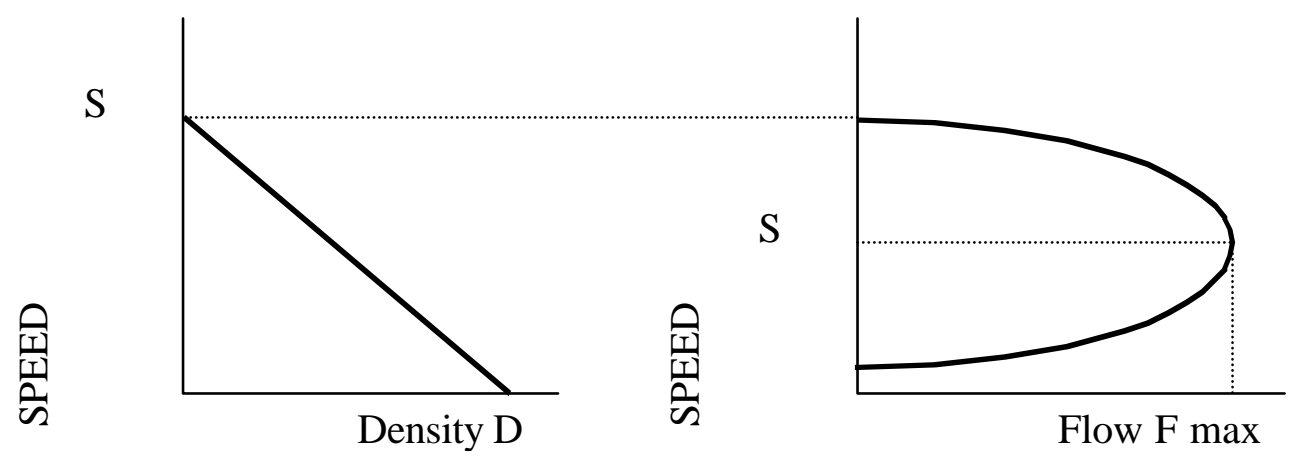

Fig. 2.1 Derivation of the speed-flow curve

Generally, analyses of congestion impacts are done over a short period of time or over the short run. This is because only relatively minor adjustments or additions can be made to the technology. Thus, increases in output or usage will result mainly in extra costs for increased wear and tear, energy consumption, and congestion.

The work of Wohl and Hendrickson (1984) is the basis of the cost functions using in this research due to their approach based on marginal cost pricing schemes.

The first cost function important in analyzing congestion pricing is the total costs over the short run for a given facility during some year $\mathrm{t}$ :

$\operatorname{SRTC}_{x, t}(\mathrm{q})=\mathrm{F}_{x, t}+\operatorname{SRVC}_{x, t}(\mathrm{q})$

Where SRTC $_{x, t}(\mathrm{q})=$ Short-Run Total Costs for a volume of $\mathrm{q}$ using facility $\mathrm{x}$ during year t.

$\mathrm{F}_{x, t}=$ fixed costs for facility $\mathrm{x}$ during year $\mathrm{t}$

SRVC $_{x, t}(\mathrm{q})=$ Short-Run Total Variable Costs for a volume $\mathrm{q}$ using facility $\mathrm{x}$ during year t.

Time per mile is obtained from the speed-flow curve by inverting speed as shown in Fig 2.2 part a. From this diagram, is easy to obtain the Short-Run Average Variable Cost (sravc). The Short Run Average Variable Cost can be obtained by multiplying time per mile by the value of travel time, and adding vehicle operating costs, as shown in Fig. 2.2 b. The Short-run average variable cost is the Short-run Variable Cost $(s r v c)$ divided by the volume q.

If we add an extra vehicle to the flow, it will impose an extra cost to the rest of the vehicles, due to a slight increase in travel time fore each vehicle. The cost associated with this 
incremental increase in flow is named Short Run Marginal Cost (srmc). The srmc curve approaches infinity as flow approaches capacity because a greater flow is impossible.

(a)

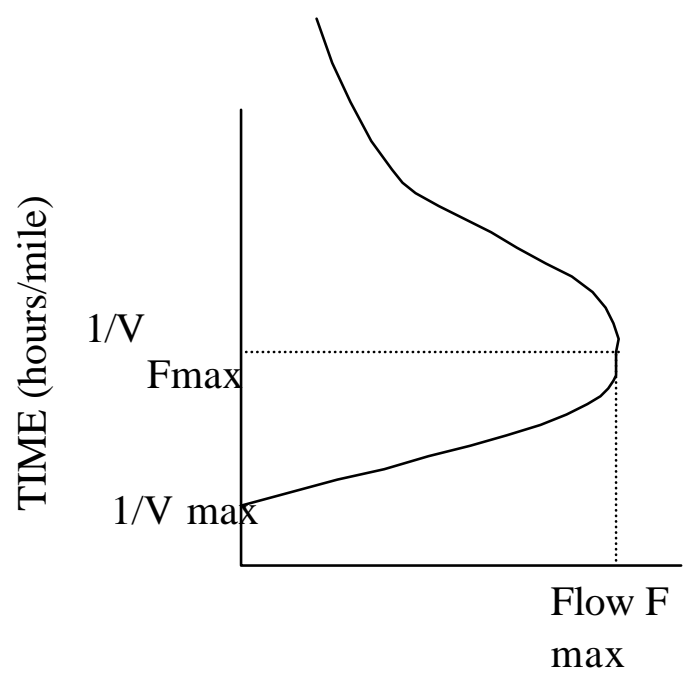

(b)

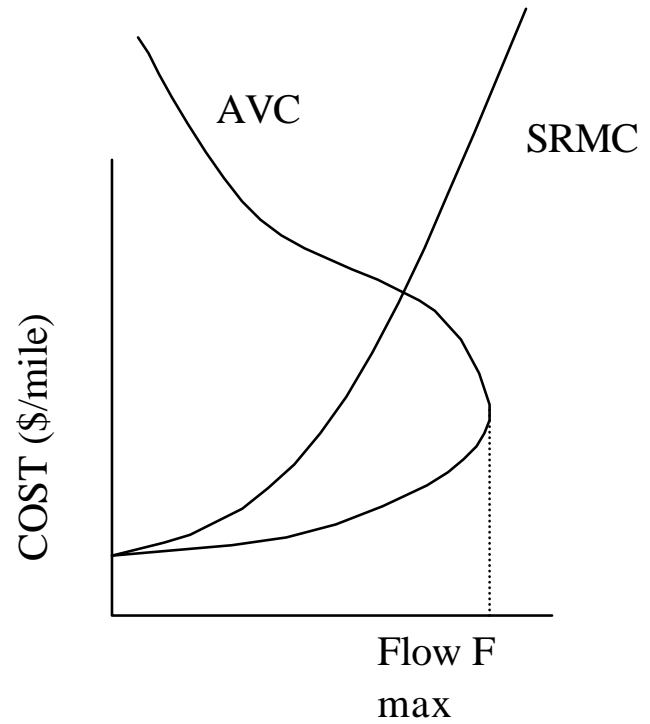

Fig. 2.2 Derivation of the cost-flow relationship.

Using the short-run total cost function we can derive the short-run average total cost, the short-run average variable cost and the short-run marginal cost as it shown in Equations 2.2 and 2.3 .

$$
\begin{aligned}
\operatorname{sratc}_{x, t}(\mathrm{q}) & =\frac{\operatorname{SRTC}_{x, t}(q)}{q} \\
\operatorname{sravc}_{x, t}(\mathrm{q}) & =\frac{\operatorname{SRVC}_{x, t}(q)}{q} \\
\operatorname{srmc}_{x, t}(\mathrm{q}) & =\frac{\partial S R T C_{x, t}(q)}{\partial q}=\frac{\Delta S R T C_{x, t}(q)}{\Delta q} \\
& =\frac{\partial S R V C_{x, t}(q)}{\partial q}=\frac{\Delta S R V C_{x, t}(q)}{\Delta q}
\end{aligned}
$$

In Fig 2.3, a demand curve, representing willingness to pay for various quantities of trips, is added to the cost curves in Figure $2.2 \mathrm{~b}$. The backward bending portion of the sravc curve is not shown because the optimal flow will never occur in this region, since the same flow can be achieved at a lower cost. In the absence of any toll, equilibrium occurs at a volume of $\mathrm{q}_{a}$, where the demand curve intersects the short-run average total costs. Thus any user, who values the trip at more than the cost he bears, chooses to travel on the facility. However, at this point, the extra 
cost to society, including the cost to other users, exceeds the benefits derived by the last traveler. This is true for all the trips beyond $\mathrm{q}_{0}$. The amount by which the additional cost of these $\mathrm{q}_{a}-\mathrm{q}_{0}$ trips exceeds the additional benefits is shown by the shaded area in Figure 2.3. This area represents the welfare loss or economic inefficiency from non-optimal pricing.

In order to eliminate this welfare loss we should restrict flow beyond $\mathrm{q}_{0}$ or impose a toll t. This toll equals the congestion externality, the difference between the cost the travelers impose to society (srmc) and the cost the traveler necessarily bears (sravc).

Restricting the flow beyond $\mathrm{q}_{0}$ is not necessarily a good and equitable measure because we cannot "segregate" users according to the value of their trip. Therefore, travelers with trip value below the benefit or at its margin, travel in place of others who have values that place them above the level of the margin.

Therefore, the best measure to ensure the elimination of the welfare loss without segregating users by their travel value is by imposing a toll. With a toll scheme, only the users who value their trip, at least as high as the marginal cost will travel.

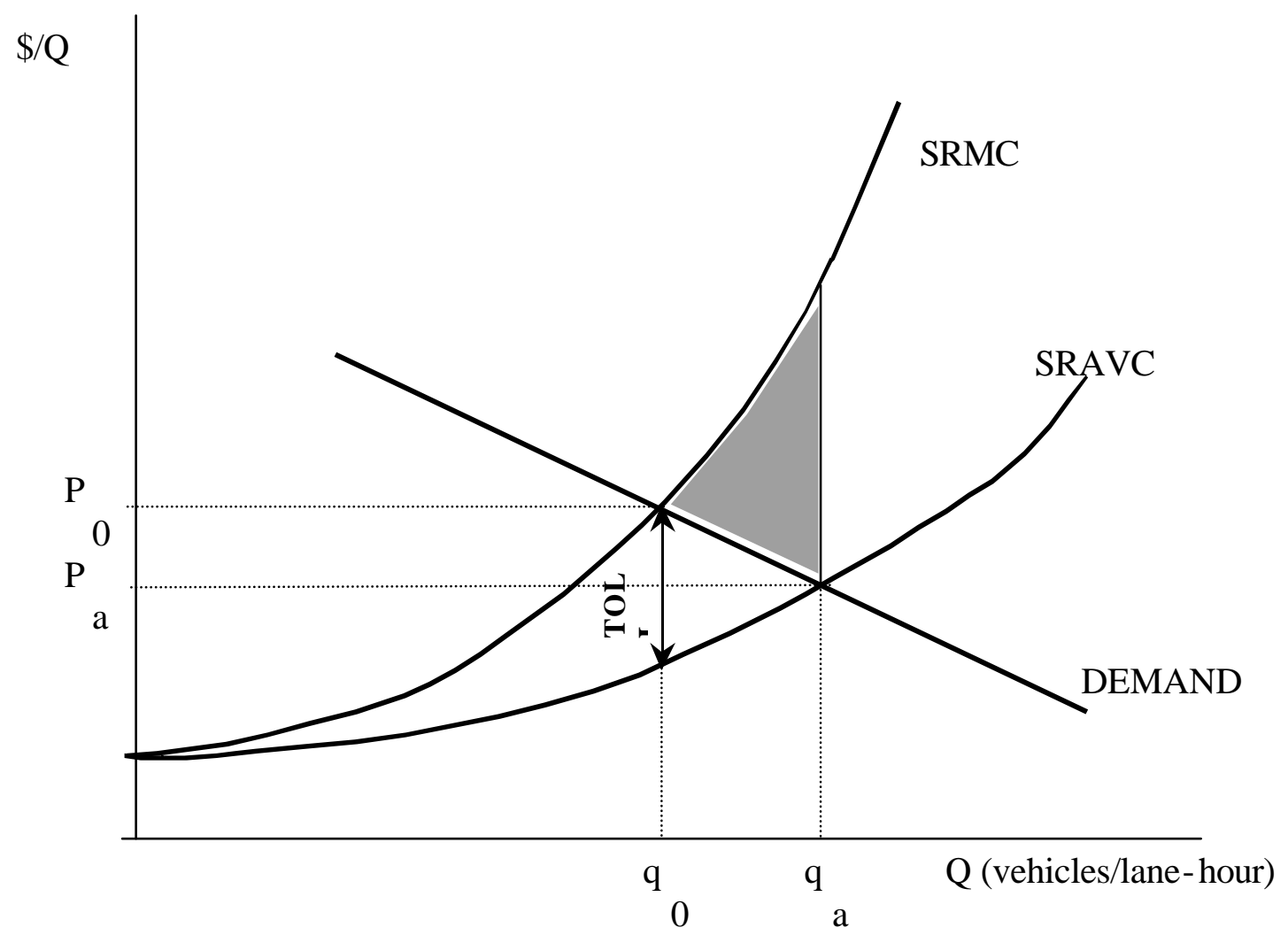

Fig. 2.3 Optimal Congestion Toll and welfare loss. 
2.1.3 Demand Functions. Demand functions are required to forecast the usage of transportation facilities and to calculate the user benefits associated with travel. The demand function relates the amount of trip making between an origin and a destination to socioeconomic conditions and the price of travel.

The travel demand functions require estimation, usually by mapping travel data with socioeconomic data. There has been extensive research published in the literature on the estimate of demand functions (Kanafani, Wohl and Hendrickson).

There are two types of observations or data commonly used in the estimation of the travel demand function: time series and cross-sectional data. Time-series observations consist of observations of each variable during various time-periods, such as annual data for a period of many years, while cross-sectional data consists of a series of observations on travel impedance (the components of the user cost), volume, and socioeconomic attributes gathered for a number of origin-destination locations at the same time.

Once we know the type of data that will be used in the estimation of travel demand, we need to associate each of these data with a variable that appears in the demand function. For example a typical demand function might be:

$q=\alpha-\beta p$

Where $q$ is the quantity of trips demanded when the price is $p ; \alpha$ and $\beta$ are constant demand parameters estimated with the use the data available.

There are several methods to estimating travel demand functions; the most widely used is the ordinary least-squares regression. This method uses the data available to estimate the actual values of the constant parameters. The problem with the estimation of demand functions using only a small number of observations is that there may be substantially uncertainty. So, it is necessary to use standard statistical tests such as significance tests to indicate the degree of uncertainty.

One important interpretation of the demand function is it is equivalence to the Marginal Benefit Function:

$q=$ Demand Function $=\alpha-\beta p$

When equation (2.6) is inverted the result is,

$p(q)=$ Marginal Benefit Function $=m b(q)=\frac{\alpha}{\beta}-\frac{q}{\beta}$

There is certain degree of sensitivity on the demand function to changes in price. The degree of sensitivity to a change in price is the price elasticity of the demand. The elasticity of demand with respect to price is defined to be the percentage change in the quantity of trips demanded which accompanies a 1\% change in price. When the price elasticity is less than 1 (in absolute value) demand is "price inelastic" and when the price elasticity is greater than 1 (in 
absolute value) demand is "price elastic." In a price inelastic condition, a percentage change in quantity of tripmaking will be less than the percentage in price. For a price elastic condition, the resulting percentage change in quantity of tripmaking will be larger than the percentage change in price.

2.1.4 Considerations for the Implementation of Congestion Pricing. Thomas Higgins in 1981 and 1986 addressed different issues and concerns with the implementation of congestion pricing. The concern is the issue of determining how road pricing revenues should be distributed. According to research done by Downs (1992), Litman (1994), Guiliano (1994), and GomezIbanez (1992), there are three somewhat competing objectives for the allocation of road pricing revenues; these are: economic efficiency, equity, and political acceptability.

\section{Economic Efficiency}

Economic efficiency involves the use of society's resources to achieve maximum net benefits. Road pricing increases efficiency by rationing road capacity with less waste than queuing. From an overall economic efficiency perspective, the revenue must be used to benefit society because it is society, through taxes, that finances the construction and operation of the transportation facilities. Under this approach, the greater the overall benefit to society, the more economically efficient the program. The revenues do tot have to be refunded to the users in proportion to their individual level of payment. Moreover, the revenues are not required to be allocated in any particular way or any specified transportation improvements, Gomez-Ibanez (1992).

\section{Equity}

Guiliano defines equity as "the distribution of costs and benefits resulting from a policy decision". According to Litman, there are two dimensions of transportation equity:

- Horizontal Equity.- implies that revenues should be returned to vehicle users as a class or roadway projects, but only after external costs (the costs of implementation and operation of the facility) are compensated. Generally, horizontal equity justification of returning revenues to users is reduced or eliminated because most estimates of external costs are larger than revenues for road pricing.

- Vertical Equity.- justifies using revenues to benefit disadvantaged people, including low-income drivers as a class and non-drivers. Vertical equity can be achieved by using revenues from congestion pricing to provide cash rebates to low-income users, to improve transit, bicycling and walking, and to fund public services to benefit the disadvantaged population.

\section{Political Acceptability}

Road-pricing programs must be attractive to voters to be acceptable. Currently, only road pricing in new highways or new road tax is politically acceptable to voters. In all cases, the revenues should be dedicated to highways resulting in a horizontal equity. In some cases, alternative distributions that include broad tax reductions or financial rebates that benefit the largest number of citizens are more political popular, Litman (1994). 
In the past, implementation and operation of congestion pricing programs was one of the most important considerations due to the lack of technology. Today, with the recent developments in computers and electronics, all the technology necessary to implement congestion pricing at a relatively reasonable cost is available.

2.1.5 Technology for Congestion Pricing. Electronic Toll Collection Systems (ETC) are the technical components that make it possible to implement a variety of congestion-pricing programs around the world. The typical ETC system consists, in part, of a tag that the driver has installed on his/her car, Figure 2.4. This tag communicates via electronic impulses with a computer located on the tollbooth. The roadside computer identifies the vehicle and deducts the monetary balance on the tag by the amount of the toll, or in case of a subsidy or refund, adds the amount to the balance. Previously, the owner of the vehicle would have had to purchase the tag and open an account with the entity in charge of the operation of the facility. This account could be a type of debit account by which every time the vehicle passed a tollbooth, the toll was deducted from a previous balance. The system also includes a type of credit by which the owner would periodically receive a statement with the balance of the account.

The ETC technology now in use around the world, has proven to be useful in implementing congestion pricing. The system has also improved toll agencies revenue collection process making it more efficient and secure. As a result, there is also a drastic reduction in congestion around toll plazas because vehicles are not required to stop. This system has advantages for the vehicle owner in the form of reduced travel time with corresponding to savings in variable costs. Finally, the system also represents a secure and efficient management of toll costs for transportation companies that require cash and coin transactions. The vehicle owner's account can include data from the trips the owner makes as well as data regarding travel patterns. These data may yield information on time-of-day, routes, peak and off-peak fares that can help not only the agency in charge of planning or operations, but can help the vehicle owner in planning their own travel patterns and costs.

Automatic Vehicle Identification (AVI) technology has made ETC possible. AVI works by using wireless communications such as radio and microwave waves between a tag (transponder) mounted on the vehicle and a sensor located on the roadside or in the toll lanes. Sensors can read the information whether the vehicle is stopped or moving at a high speed. The communication between the tag and the sensor can be one way (read-only) or two way (read/write). 


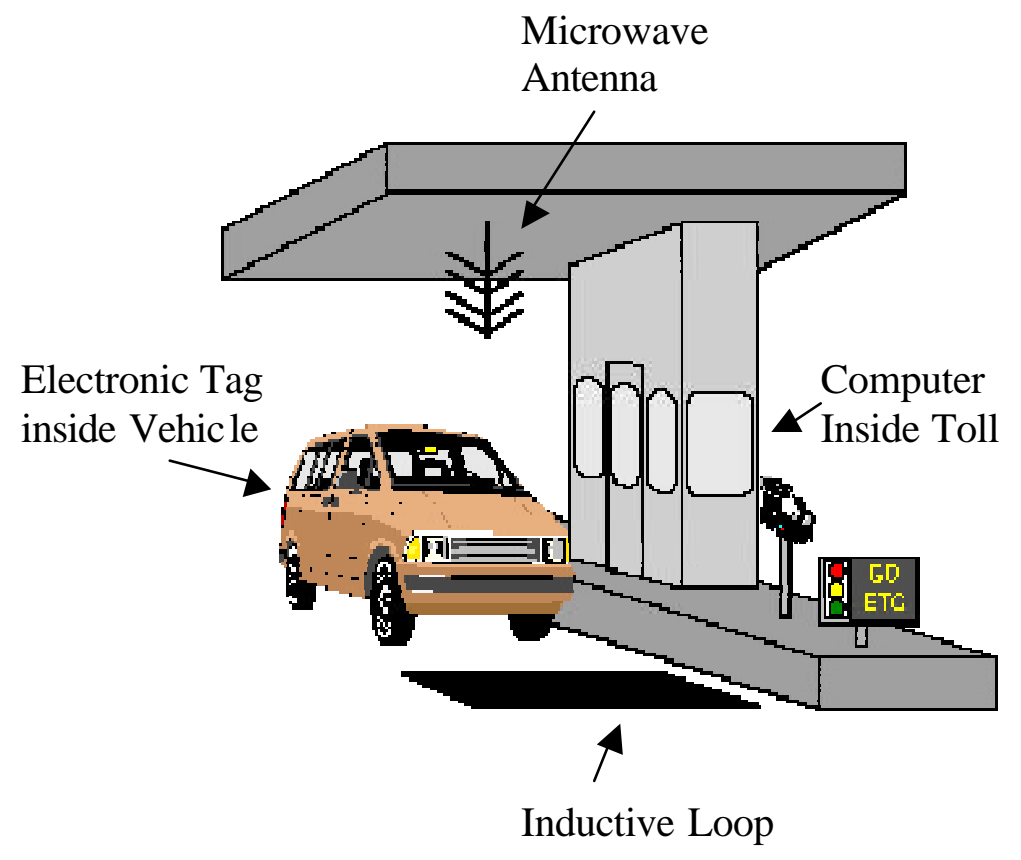

Fig. 2.4 Electronic Toll Collection System

All present AVI/ETC technologies operate by an intercepting modulated electromagnetic radiation from a vehicle, by recovering the information contained in the signal, and by using a computer to identify the tag from a database. This technology has been in operation since 1994 as Pietrzyk mentioned. There are different AVI/ETC technologies available today; the most important are the following:

- Inductive Loop Systems. This technology uses a loop antenna embedded beneath the surface of the roadway to communicate with a tag mounted on the underside of the vehicle. The roadway antenna sends out an interrogation signal and the tag responds by returning a signal containing the data stored in the tag. This is the oldest AVI/ETC technology in use.

- Optical Systems. These systems utilize a video camera to capture the license plate of the vehicle and digitized it. This information is then compared with a database. Another optical system works with a laser that scans a bar code mounted on a specified location on the vehicle. The code is compared with a database. Generally the laser system is simpler than the video camera system.

- Active Radio Frequency/Microwave Systems. These systems utilize microwave frequencies to communicate the data between the tag and the computer. This communication can be active (tag generates its own microwave signal) or passive (tag simply reflects microwave signal).

- Passive Radio Frequency/Microwave Systems. In this system, a transmitter at the tollbooth usually transmits a continuous signal. The signal is intercepted by the tag and reflected to a receiver. The received signal is decoded to recover the data that are send to a computer for identification. 
The ETC technology now in use around the world has proved that most of the congestionpricing programs can be implemented. In addition, automation of toll collection can reduce congestion around toll plazas, increase energy efficiency, and reduce indirectly the emissions. ETCs also can promote ridesharing programs and spread the traffic out of the peak period, Pietrzyk (1994). Figure 2.4 shows the basic elements of the ETC system.

\subsection{Tolling Systems}

A toll system is one of the methods of implementing congestion pricing to charge users the marginal cost they impose on others. This toll must be equal to the difference of the Short Run Marginal Cost (srmc and the Short Run Average Variable Cost (sravc). Recall that sravc are the costs that users necessarily bear, such as fixed and operating costs. In order to maximize total net benefits this toll should be imposed.

There are two basic methods of tolling systems: the Time-Varying Tolling System and the Step Tolling System. It is important to review the characteristics of each one of these systems to understand how they operate.

2.2.1 Time-Varying Toll System. Every time that there is a change in the demand function (a shift up or down) due to a change in the socioeconomic conditions, it is necessary to adjust the toll to preserve benefit-maximizing conditions. This toll adjustment is the only possible way to charge users the marginal cost they impose to themselves and others (or the difference between srmc and sravc). Figure 2.5 represents a Time-Varying Toll. This system can serve as an approximation to toll users according to the real conditions of demand but not the most practical and economical efficient system as Arnott and de Palma (1990) mention.

In the past, the technical obstacles to implementing the Time-Varying Toll System were difficult. Today, with the new developments in Electronic Toll Collection, it can be technically feasible to install and operate a time-varying toll system. So, why is it that if Time-Varying toll systems are the most accurate and technically easy to implement, these tolling systems are not widely in use? The answer to this question is, from the user's point of view, a pure TimeVarying Tolling System is not understandable. Imagine a user that is charged a toll of one dollar for the use of facility $X$ at 7:00 am. A second user arriving at facility $X$ at 7:10 am, is charged $\$ 1.10$ because the demand function just changed, perhaps due to a higher traffic flow. If the users compared their tolls, the second user will feel that he has been charged 10 additional cents just for being at the booth ten minutes later than the first driver. The users will not understand about the marginal cost they impose on the system or the shifts in the demand functions due to a change in the socioeconomic conditions. 


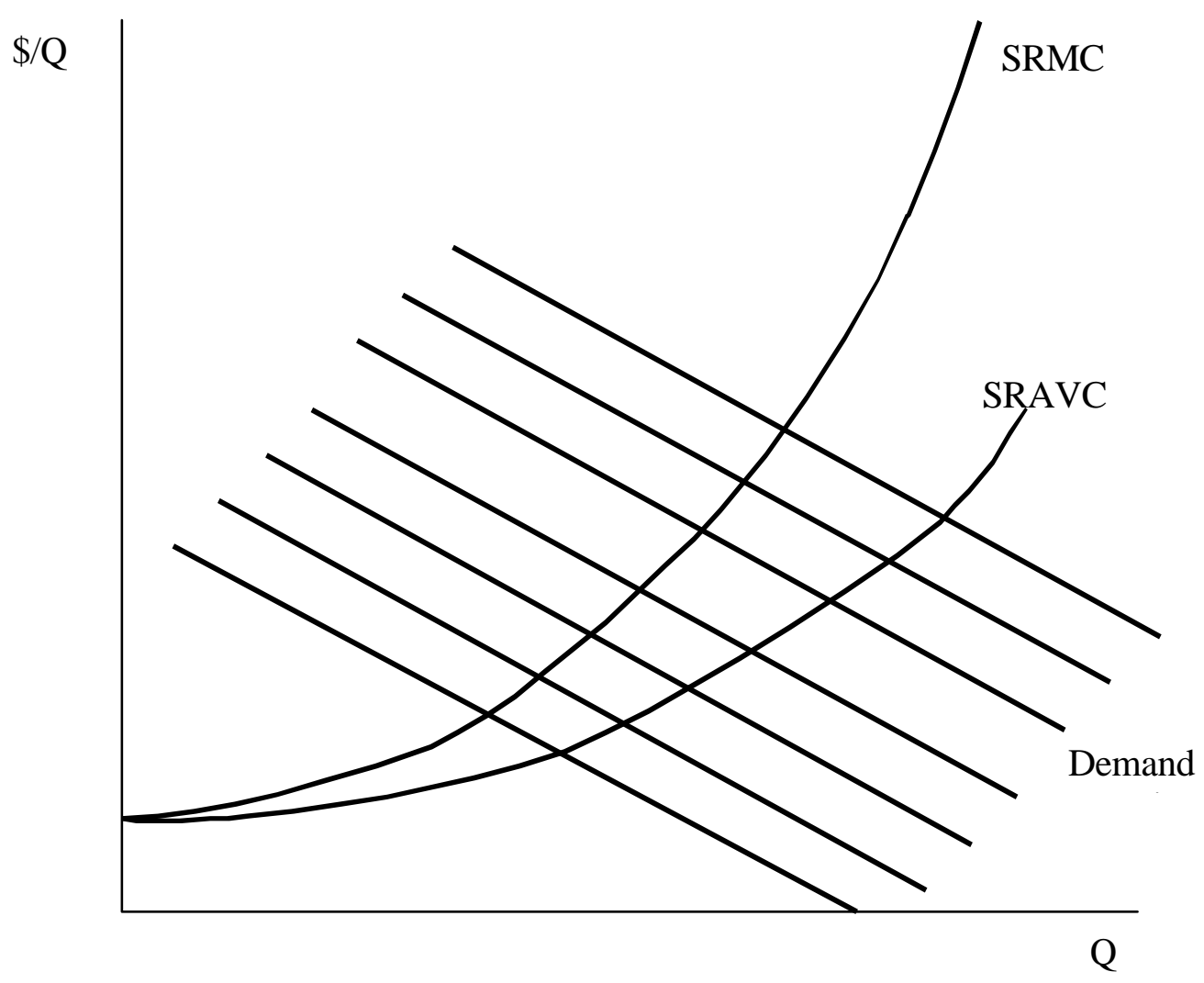

Fig. 2.5 Time-Varying Toll

2.2.2 Step Toll Systems. Step Toll Systems are a more practical response to changing demand through discrete variations (or steps) in the optimal Time-Varying toll.. These variations consist of charging a toll according only to important changes in the demand function at certain times of the day. These changes can be, for example, the shift from off-peak periods to peak periods when the demand abruptly changes due to higher number of vehicles on the facility. Figure 2.6 represent the step Toll systems. A step toll system is now implemented on Interstate 15 near San Diego California. This variation of the Time-Varying toll system is easier to implement and understand by the users.

Laih (1994) suggests that if any given period of time, only one toll is charged, then the tolling system may be termed a "single step toll system". However, if the toll is changed two or more times during any given time period, the toll system may be termed a "multiple step toll system. The "steps" therefore are the number of tolls changed and charged in a period of times. 


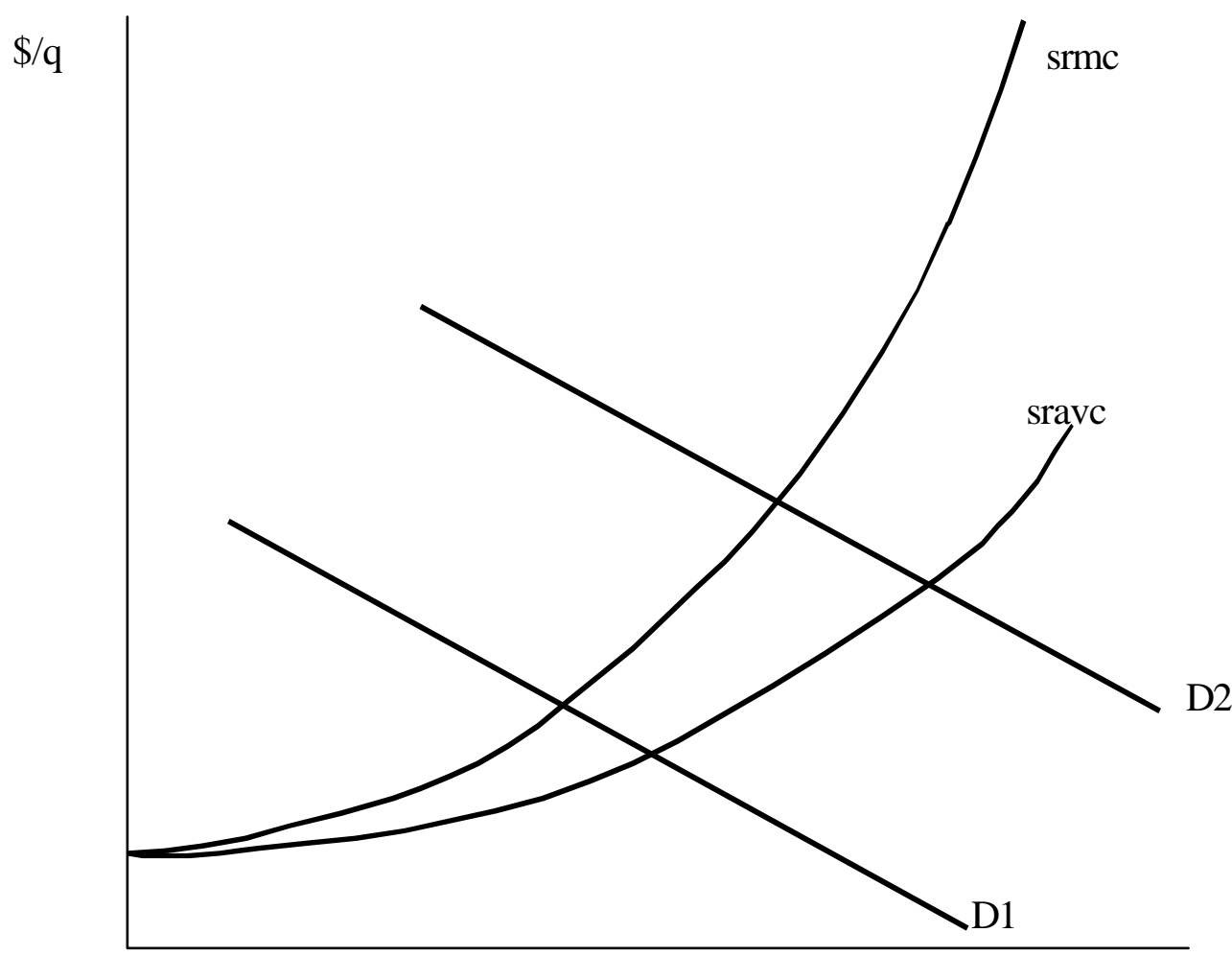

q

Fig. 2.6 Step Toll System

\subsection{Other Traffic Congestion Relief Alternatives}

Congestion pricing is not the only alternative to reduce congestion. Some of these alternatives are already implemented. Downs (1992) recognizes these alternatives as increasing carrying capacity, demand-side remedies, and supply-side remedies. Later in 1993, the United States Department of Transportation issued a report of the possible measures and benefits from the implementation of Transportation Demand Management.

The most important proposed measures are the following:

- Increasing carrying capacity of the existing system. This idea includes not only building more roads or widening the existing ones, but also includes less invasive tactics making traffic flow faster, such as Transportation Management Systems. Transportation Management Systems include; coordinated traffic signals, High Occupancy Vehicle facilities, High Occupancy Toll facilities and reversible lanes. It also includes construction and maintenance management, accident response systems, parking 
management, and the new improvements in Intelligent Transportation Systems such as the use of Automatic Traveler Information Systems (ATIS) or ETC systems. The increasing of carrying capacity is not only limited to highways, but also extends to the public transit systems.

- Demand-side remedies focus on behavior and the benefits from accessibility to spatially separate activities. These tactics try to change the way people behave within the existing transportation systems and settlement patterns. Some of these tactics include: incentives to shift users from peak periods to other periods such as staggering work hours, flextime policies, or shortening working days on the week; telecommuting that is using the new improvements in communications and computers to work at home instead to commute daily to an office; restricting the days on which owners can use their vehicles, encouraging ride sharing, increasing the costs of using private automobiles, increasing the cost of parking, and encouraging use of public transit.

- Supply-side remedies. These tactics include a planning and design process contemplating actual and future growth with the adequate transportation system.

\subsection{Summary}

The literature addresses several aspects of the congestion problem and measures such as Transportation Demand Management measures to relieve it. Congestion pricing has been an issue of intense study and also intense debate. From the point of view of economists and some transportation engineers, it is a promising measure to relieve congestion. However, from the point of view of users and elected public officials, congestion pricing is still highly controversial.

The literature reviewed in this chapter addressed the first attempts of congestion pricing as a possible measure to relieve congestion. Then the literature review presents an overview of the research in the field of marginal costs pricing and toll systems as the way to implement congestion pricing. Finally the literature review summarizes the technology available to implement different tolling systems and summarizes also other possible congestion relieve alternatives.

As mentioned before, there has been a great amount of research in the area of congestion pricing and tolling systems, however the literature has an important void that this research will try to fill. Specifically there is a need to study the implementation of different step toll systems from the point of view of the economic savings that their implementation can cause to the users and the system. It is important to study how the economic savings from every toll system can be a reliable economic parameter to consider on an evaluation process. 


\section{Chapter 3. METHODOLOGY}

\subsection{Introduction}

This chapter explains the methodology used to assess the conditions by which stepped tolls may yield economic advantages relative to single tolls. First, it is necessary to obtain and value the demand, and second, it is necessary to value the costs involved in the system. Knowing about the demand and the costs involved calculating the single or double tolls is possible. To obtain the savings between both systems it will be necessary to develop a function that involves the savings of the single toll, and then compare this function with the savings of the double step. In addition, it is important to consider a methodology to compare savings between single and multiple-step toll systems. Going one step further, it is possible also to calculate the reduction in congestion using single and double step tolls.

Previous research in this field did not demonstrate a way to calculate and compare different tolling systems using the savings that each system represents when it is imposed. Unfortunately, the idea of marginal cost pricing is still in theory. Therefore, there are no systems operating on the basis of pure marginal cost pricing around the world.

The procedure followed in this research work consists of four fundamental tasks.

1. Develop a Single-step toll model to obtain a single-step toll consistent with marginal cost pricing and the savings related to the imposition of this single toll over a variable cost pricing.

2. Develop a Double-step toll model. The next step in the model is the calculations of the double toll imposed in a double-step toll system and the savings obtained from this system.

3. Conduct experiments involving the model. The model is applied in several practical cases. The experiments proposed in this research work are the following:

- Peak and Off-peak periods setting on an urban road. Using single and double-step tolling systems as a congestion relief measure.

- Peak and Off-peak periods on a high volume highway. Using single and doublestep tolling systems as a congestion relief measure.

Each experiment will be performed in four different scenarios in order to have a valid set of results for different scenarios in each experiment. The scenarios proposed for each experiment are the following:

- Increase and decrease on the different demand functions

- Use of different price elasticities in each Demand Function (Low and High demand cases)

- Use of different opportunity cost of travel time.

The first three scenarios will try to reflect the movement on the demand functions due to changes in socioeconomic conditions and how this movement affects the relative benefits of the toll schemes. The last scenario will directly affect the cost functions (sravc and $s r m c$ ) and how this movement in the cost functions affects the output of the model. 
4. Analysis of experimental results. Once the model has been applied to each one of the scenarios, it will be possible to make an analysis from outputs. The analysis consists of computing the amount of savings obtained from each tolling system, the amount of queue removed and amount of the toll related to the different experiments and scenarios.

\subsection{Single Step and Double Step Toll Models}

It is important to show the development of the single and multiple step toll systems based on the basis of Wohl's and Hendrickson's research.

- Development of the Single Step Toll System. Using Figure 2.3 in Chapter 2, we are able to develop a single step toll system that is the simplest toll system. With only one demand curve $(\mathrm{D}(\mathrm{q})$ or $\mathrm{mb}(\mathrm{q}))$, the $\operatorname{srmc}(\mathrm{q})$ and the $\operatorname{sravc}(\mathrm{q})$ we are able to obtain a toll equal to the difference of the $\operatorname{srmc}(\mathrm{q})$ and the $\operatorname{sravc}(\mathrm{q})$ at a volume of $\mathrm{q}_{0}$. This is the optimum toll for a volume not higher than $\mathrm{q}_{a}$.

The total savings obtained from the single step toll system $\left(\mathrm{S}_{s s}\right)$ are indicated by the dashed area in Figure 2.3. and are equal to:

$$
\mathrm{S}_{s s}=\sum_{q=q_{0}}^{q_{q}} \operatorname{SRMC}(p)-\sum_{q=q_{0}}^{q_{q}} m b_{l}(p)
$$

- Development of the Multiple Step Toll System. Using only 2 different tolls or "steps" is the simplest case of the Multiple Step Toll System. To obtain this pair of tolls, it is necessary to establish a second demand curve that comes from an increase in demand, from a different value of travel time, from a different type of vehicle or from any other reason. To make it easier to understand, let us refer to the demand curve with the lowest volumes a Low Demand Curve $\left(\mathrm{D}_{L}\right)$ this is basically the demand that we use in a singlestep toll system, and the demand curve with the highest volumes a High Demand curve $\left(\mathrm{D}_{H}\right)$. In general, each of the two demand curves will intersect the srmc curve and the sravc curve at different volumes. The Demand Low curve will intersect the $s r m c$ curve at $\mathrm{q}_{0}$ and the $\operatorname{sravc}$ at $\mathrm{q}_{a}$.

The High Demand curve will intersect the $\operatorname{srmc}$ curve at $\mathrm{q}_{b}$ and the $\operatorname{sravc}$ at $\mathrm{q}_{c}$. The toll for a case of Low Demand $\left(\mathrm{D}_{L}\right)$ will be the difference of the srmc and the sravc at a volume of $\mathrm{q}_{0}$. The toll for the case of High Demand $\left(\mathrm{D}_{H}\right)$ will be the difference in srmc and sravc at a volume of $\mathrm{q}_{b}$.

The savings $\left(\mathrm{S}_{S S}\right)$ using the Low Demand Toll or single step toll are computed by Equation (3.1)

The savings with a High Demand toll $\left(\mathrm{S}_{D S}\right)$ or double-step toll are equal to:

$$
\mathrm{S}_{D S}=\sum_{q=q_{b}}^{q_{c}} S R M C(p)-\sum_{q=q_{b}}^{q_{c}} m b_{H}(p)
$$


The volume $\mathrm{q}_{a}$ at Low demand and $\mathrm{q}_{c}$ in High Demand are the maximum allowed in the facility for each case. The difference between $\mathrm{q}_{c}$ and $\mathrm{q}_{b}\left(\mathrm{q}_{c}-\mathrm{q}_{b}\right)$ is the "tolled off" users from the change of single step toll system to double step toll system.

If a new Demand arises, it is necessary to implement a new multiple-step toll system with three, four, five or n "steps" or tolls according to the number of demand functions from where it is necessary to impose a toll. The process will be similar to the double-step toll system and the corresponding savings will be:

Savings Multiple-Step $=$ Savings Single-Step + Savings Double-Step + + Savings Triple-Step + ... + Savings N-Step

3.2.1 Step 1.- The Demand Function.-- As already mentioned in the Chapter two, the demand function represents the willingness to pay (thus benefits) for various quantities of trips. Certainly Demand Functions will be used in the calculations because are the basis to understand how users react to changes in various factors especially changes in the price of travel. Obtaining the demand function can be a difficult task due mostly to the availability data such as number of trips and willingness to pay for trips. Likewise, the demand function is only our best estimation of the actual and future conditions of the demand of trips, and sometimes cannot reflect the real conditions of the demand of trips.

When there is a change in the socioeconomic conditions (increase or decrease), as represented in Figure 3.1. such as population or income, there will be a shift or movement of the demand curve. That is, the demand could increase or decrease in response to such changes. This is the case of a multiple-step toll system. In this system, there is a move of the demand curve to adjust to certain changes. Therefore, it will also become necessary to adjust our toll to the new demand and volumes of the new conditions of the demand.

Using the Equation (2.6), it is possible to obtain the demand functions for the case of a single and a double-step toll system. In the case of the single-step toll system, having a low demand situation $q_{L}$ where the socioeconomic conditions require a single toll $T_{L}$, named this case a "low demand single-toll system". There are cases where we have a "low demand" and "high demand" conditions on the facility. In order to reflect these changes and charge the users a toll according to the conditions of the demand, a double-step toll system is required. In the case of double-step tolls, a toll $T_{H}$ will be applied during the high demand conditions $q_{H}$. In a single step toll system, if a new demand appears (a high demand) and only a toll for the low demand is charged the system have economic losses. The total net benefits are not maximized; and there are inefficiencies in resources allocation. On the other hand, if in a single-step toll case, a toll for high demand conditions is charged and there are only low demand conditions, there are tollingoff users who cannot afford to pay a high demand toll.

Because demand may be referred to as Marginal Benefit function, the corresponding pair of equations for the demand functions and their inverses for the marginal benefits are:

$q_{L}=\alpha_{L}-\beta_{L} p$ 
$q_{H}=\alpha_{H}-\beta_{H} p$

Inverted:

$\mathrm{mb}_{L}(\mathrm{q})=\frac{\boldsymbol{\alpha}_{L}}{\beta_{L}}-\frac{q}{\beta_{L}}$

$\mathrm{mb}_{H}(\mathrm{q})=\frac{\boldsymbol{\alpha}_{H}}{\beta_{H}}-\frac{q}{\beta_{H}}$

Where $q_{L}$ is the quantity of trips demanded when the trip price is $\mathrm{p}$ in a low demand case. $\alpha_{L}$ and $\beta_{L}$ are the parameters for the socioeconomic conditions in the case of low demand. $q_{H}$ is the quantity of trips demanded when the trip price is $\mathrm{p}$ in a high demand case. $\alpha_{H}$ and $\beta_{H}$ are the parameters for the socioeconomic conditions in the case of high demand and $m b_{L}(q)$ and $\mathrm{mb}_{H}$ (q) are the marginal benefits for the case of low demand and high demand respectively.

Once the demand functions have been obtained it is possible to continue with the rest of the calculations.

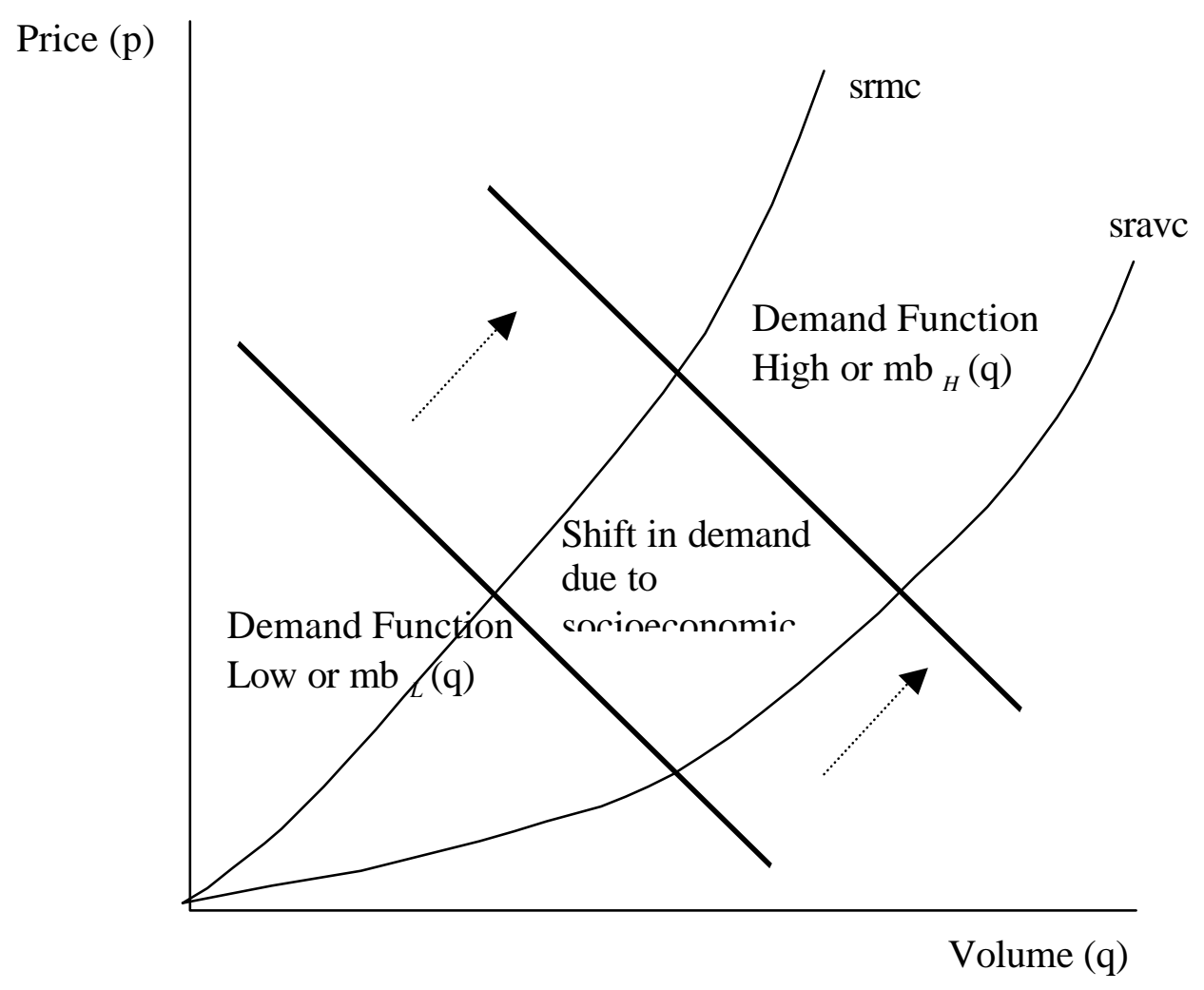

Figure 3.1 Shifts in Demand Function

3.2.2 Step 2.- Short Run Average Variable Costs ( $\mathrm{rravc}$ ).- One of the most important parameters involved in the short run average variable cost is the value of travel time. Each person values his/her time according to different socioeconomic conditions and according to the characteristics 
of the trip, especially the travel time. We would expect, economically speaking, that people who commute every morning to work values this trip more than a weekend trip to the movies. Therefore, it is necessary to place a monetary value on travel time. The way to obtain the value of travel time is to use a large number of similar observations of travel time values to derive an estimated value or formula for the value of time using statistical techniques.

First, it is necessary to estimate the travel time on a roadway in order to obtain a value for this time. For an individual road or facility, the travel times may be estimated by observing actual trip times on the facility, however this is impractical for large transportation networks. For large facilities it will be necessary to develop a model to estimate travel times indirectly. These models are generally called performance functions, and they relate the travel time on a particular type of facility to the characteristics of the facility, vehicle fleet mix, and volume of the travel.

The performance function develop by Walters A (1968), used for estimating the travel time is:

$t=\frac{1}{V_{\max }-\delta q} \quad$ for $\quad q<\frac{V_{\max }}{\delta}$

where $t$ is the travel time per mile over the link, $V_{\max }$ is the average speed on the link when volumes are very low, $q$ is the volume actually using the link, and $\delta$ is the parameter related to the capacity of the link. Figure 3.2 shows the travel times for different volumes using Equation (3.7).

It is necessary to mention that the travel times are only reasonable estimates of actual times and, thus, are uncertain. As a result, the estimated costs associated with travel times will also be uncertain.

Once the travel time has been obtained the next step is to place a value to travel time. There are several studies of the value of travel time, Chui and McFarland estimated the value of travel time using a speed-choice model where the user choose the route with higher speed in order to reduce their travel time. They recommended a value of travel time of $\$ 10.38$ per vehicle hour (1985 value), Appendix B shows the translation of this value to year 2000 value and is equal to $\$ 16.50$ per vehicle hour.

Another parameter involved in the calculation of the sravc is the value of the fixed vehicle costs, which do not vary with speed or time; these costs can be the ownership of the vehicle, registration fees, insurance and ownership taxes. It sometimes can be difficult to obtain a good estimate for these costs because, roads have a mix of vehicles with different fixed costs. The best estimate would be the one that best reflects the distribution of vehicle types.

According to the data available from the American Automobile Association, the average fixed cost for an automobile is 37.41 cents per mile (1998 value). Appendix B shows the translation of this value to year 2000 value equal to 39.65 cents. 


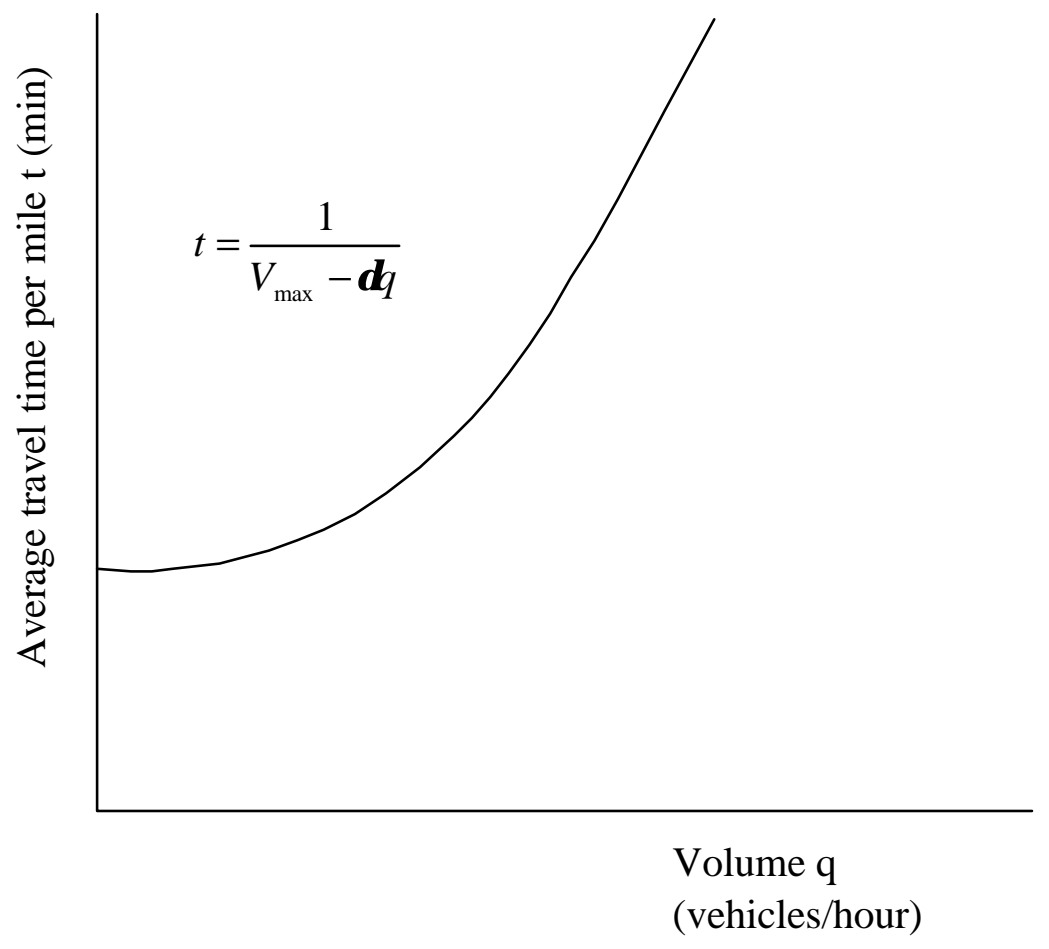

Figure 3.2 Roadway Performance Function

Using the value of travel time and the fixed costs which are invariable with speed, it is possible to obtain an equation for the short run average variable costs ( $\mathrm{ravc}$ ) According to Walters:

$$
\operatorname{sravc}(q)=\tau+\frac{v}{(V-\delta q)}
$$

in which

$\operatorname{sravc}(q)=$ average variable costs to users for a volume of $\mathrm{q}$, in cents per vehicle mile

$\tau=$ portion of average variable cost which is invariant with speed

$\mathrm{V}=$ average speed on the facility at low or near-zero levels of volume, in mph

$\delta=$ speed reduction parameter for the facility

$v=$ value of travel time and effort, in cents per vehicle-hour

$q$ = flow rate or volume on the facility, in vph

Once the short run average variable cost have been calculated, the next step is the calculation of the costs that an extra user imposes to itself and the others, defined as the short run marginal cost. Figure 3.3 shows this.

Together the srmc and the sravc will give us the two most important cost curves for the model, and using both curves and the demand or marginal benefits curves it is possible to obtain the toll and the savings for each system. 


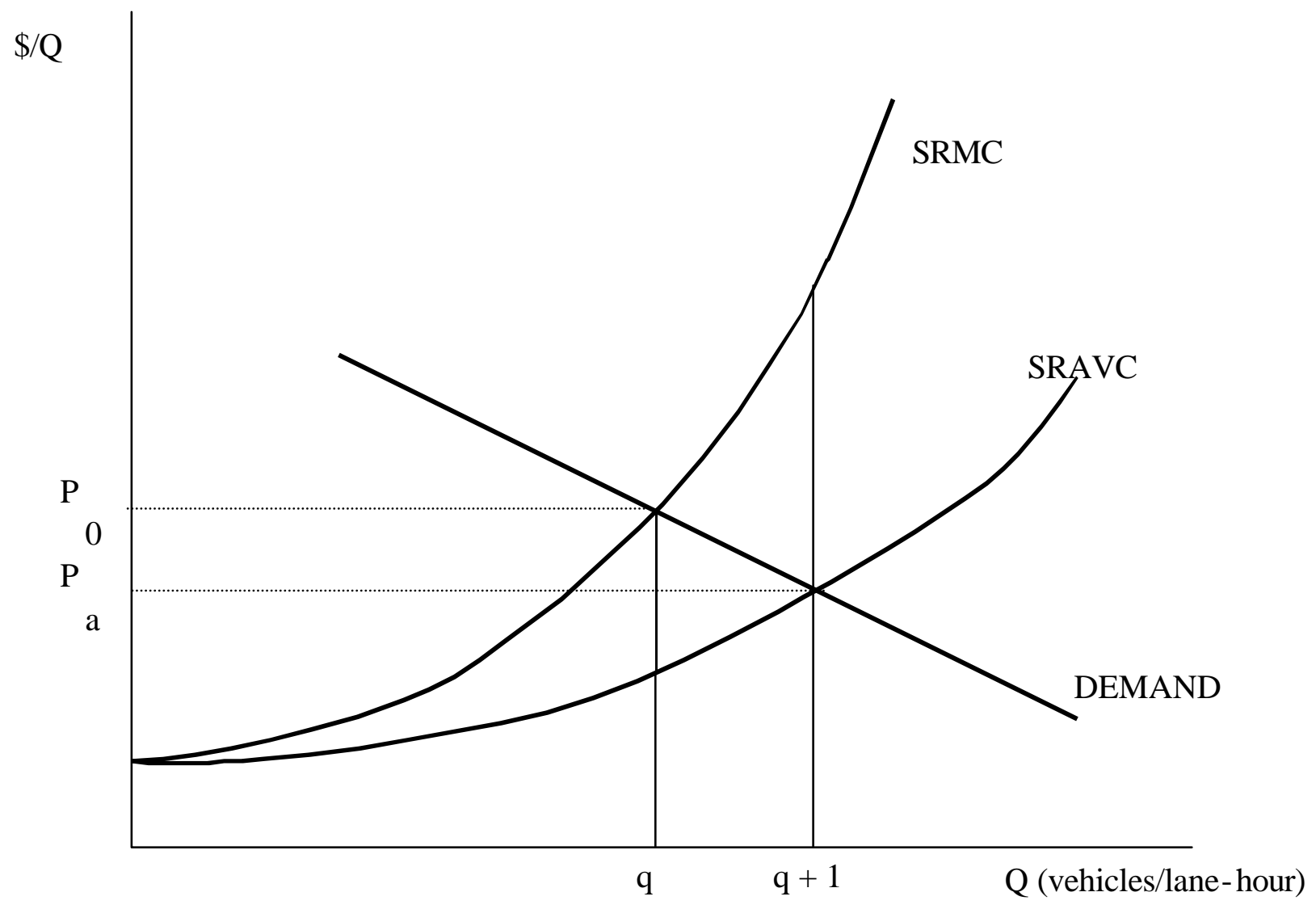

Fig. 3.3 Cost of an extra user on the facility

3.2.3 Step 3.- Short Run Marginal Cost (srmc).- When a new vehicle enters the facility, the user will experience only the short run average variable costs as long as no tolls are imposed. As long as the facility operates under free-flow traffic conditions this cost will be the only one in effect, but when the traffic flow conditions become saturated, each additional vehicle that enters the system will impose an extra delay on other users.

Charging every new user with the total costs they impose is called marginal costs pricing. The calculation of the equation for the short run marginal cost is easily obtained from the sravc equation. The srmc can be obtained by deriving the $\operatorname{sravc}$ as shown in chapter 2 equation (2.5):

$\operatorname{srmc}(q)=\frac{\partial S R V C}{\partial q}=\frac{\partial q * \operatorname{sravc}(q)}{\partial q}$

Using equation (3.8) and (3.9) $\operatorname{srmc}(\mathrm{q})$ is equal to: 
$\operatorname{srmc}(q)=\tau+\frac{v}{(V-\delta q)}+\frac{v \delta q}{(V-\delta q)^{2}}$

Applying Algebra, Equation (3.10) can be reduced to:

$$
\operatorname{srmc}(q)=\tau+\frac{v V}{(V-\delta q)^{2}}
$$

If a marginal cost pricing is imposed all the users should be affected in some way. Usually the affected users can be divided in three groups: the tolled, the tolled off and the untolled.

1. The tolled users. When marginal cost pricing is imposed, a congestion toll equal to the difference of $s r m c$ and $s r a v c$ for a volume equal to $\mathrm{q}_{a}$ will be charged, bringing the total price $\mathrm{p}\left(\mathrm{q}_{a}\right)$, to $\operatorname{srmc}\left(\mathrm{q}_{a}\right)$ and resulting in a reduced flow rate of $\mathrm{q}_{a}$ as shown in Figure 2.3. While all the $\mathrm{q}_{a}$ users having a trip value which is at least as high as $\mathrm{p}\left(\mathrm{q}_{a}\right)=$ $\operatorname{srmc}\left(\mathrm{q}_{a}\right)$ will be willing to pay that price to do the trip, they are worse off than they were with the average variable cost pricing. Simply, they have to pay a higher price to travel.

2. The tolled off. The users who were tolled off are clearly worse off after the change in pricing policy. They were "forced" to move from a preferred situation into a less preferable situation just because they are unwilling to pay the congestion toll and higher overall price. They will have to look for an alternative mode of transportation, alternative routes or they have to shift to another period of time to travel. It is important to offer alternatives to this type of users before implementing a marginal cost pricing policy.

3. The untolled. Untolled users are those travelers on travel facilities to which some tolledoff users divert after the change to marginal cost pricing. Even untolled users of transport facilities are made worse off by the shift to marginal cost pricing. Travel modes or routes became more congested due to both the untolled and the tolled-off users, relative to the situation which existed prior to the price change.

Once we have the srmc and the sravc the next step is the calculation of the toll for a single and double step system, and also the calculation of the savings.

3.2.4 Step 4.- Single Step Toll and the calculation of the Function for a Single Toll (LT).- In order to impose marginal cost pricing, it is necessary to charge users with a toll equal to the extra costs they impose on the others. A single step toll is one good method to charge these extra costs but it does not vary with shifts in demand. A reasonable hypothesis is that for a low demand case, a single-step toll system is sufficient in imposing this extra cost, because it easy to implement and may not have substantial gains over sravc pricing. Most toll facilities around the world operate under this scheme, but the amount of the toll is not established based on congestion but rather is based on paying operation and maintenance costs of the facility. 
The single toll is calculated from the difference between the short run marginal cost and the short run average variable costs at the point where the Low Demand function (or marginal benefits) intersects the srmc curve as shown in Figure 3.4.

Using Equation (3.8) and (3.11) it easily to calculate the single toll:

$T_{\text {Low }}=\operatorname{srmc}\left(q_{0}\right)-\operatorname{sravc}\left(q_{0}\right)$

Substituting equation (3.9) and (3.11) into (3.12) and solving we have:

$$
T_{\text {Low }}=\frac{v \delta q_{0}}{\left(V-\delta q_{0}\right)^{2}}
$$

For a volume $(q)$ where $\operatorname{srmc}(q)=$ Demand Function.

When a shift in the demand function from a "low" to a "high" case occurs it is necessary to change the toll in order to keep imposing marginal cost pricing. In this case, it is necessary a function that yields the amount of savings obtained from this change. For this purpose, a function named "Low Toll" (LT) is defined, which is equal to the short run average variable costs plus the single step toll (low demand toll). With this function it is possible to reflect the savings obtained with the single toll (low demand toll) onto the savings of the double-step toll (high demand toll) for a comparison.

The Low Toll function can be obtained using Equations (3.8) and (3.13):

Low Toll Function $(\mathrm{LT})=\operatorname{sravc}(q)+T_{\text {Low }}$

Using Equations (3.8) and (3.14) we have:

Low Toll Function $(\mathrm{LT})=\tau+\frac{\mathrm{v}}{(V-\delta q)}+T_{\text {Low }}$

3.2.5 Step 5.- Savings from imposing the Single Toll or Low Demand Toll.- If a toll is not imposed and the users only cost is the sravc, then the system will reflect a loss in the welfare. In contrary, if a toll is impose to make the users pay their marginal cost this welfare loss is transformed into savings for the system.

The dotted area in Figure 3.4 shows the Single Step savings. Using equation (3.1) it is possible to obtain the savings from imposing a single-step toll (or low demand toll) as follows:

$$
\mathrm{S}_{s s}=\sum_{q=q_{0}}^{q_{q}} \operatorname{srmc}(p)-\sum_{q=q_{0}}^{q_{q}} m b_{L}(p)
$$


Using Equation (3.4) and (3.11) we have:

$\mathrm{S}_{s s}=\sum_{q=q_{0}}^{q_{a}}\left(\tau+\frac{\mathrm{v} V}{(V-\delta q)^{2}}\right)-\sum_{q=q_{0}}^{q_{a}}\left(\frac{\boldsymbol{\alpha}_{L}-q}{\boldsymbol{\beta}_{L}}\right)$

It is important to mention that if the savings obtained from the single-step toll system are lower than the implementation and operation costs this result in an economic loss. Thus, the system is not economically efficient and it is necessary to explore other pricing alternatives.

Once the savings for the single toll system have been calculated the next step is to analyze the case of a shift in demand that produces the causes to consider a new toll. This new toll will carry a new calculation of savings. Then it is possible to make a comparison of the savings from the single-step toll versus the savings of the double-step toll system.

3.2.6 Step 6.- Double-Step Toll and calculations of the Function for a Double Toll (HT).- As mentioned before, a case of a double-step toll system occurs when there is a shift in the demand function usually due to several socioeconomic reasons. This shift in demand requires calculation of a new toll in addition to the previous single-step. It is important to mention that the doublestep toll should apply as soon as there is a shift in demand. Therefore, with a volume of more than $q_{b}$ but less than $q_{c}$, the "high" demand toll charged to the users in order to avoid any welfare loss and also avoid traffic congestion as shown in Figure 3.4. The calculation of the double-step toll is the difference of the short run marginal cost and the short run average variable costs at the point where the High Demand function (or marginal benefits) intersects the srmc curve as shown in figure 3.4 .

Using Equation (3.8) and (3.11) it easy to calculate the double-step toll:

$T_{\text {High }}=\operatorname{srmc}\left(q_{b}\right)-\operatorname{sravc}\left(q_{b}\right)$

Substituting equation (3.8) and (3.11) into (3.18) and solving we have:

$$
T_{H i g h}=\frac{v \delta q_{b}}{\left(V-\delta q_{b}\right)^{2}}
$$

For a volume (q) where $\operatorname{srmc}(\mathrm{q})=$ High Demand Function.

Going one step further, if a new shift in demand occurs, then it may be necessary to impose a new toll in order to avoid a welfare loss in the system. The new toll imposed will carry new savings to the system. It will be necessary then to compare these new savings of imposing a "triple-step" toll system with the savings from the double-step toll system. The way to do this comparison is also by using a function to relate the savings from a double-step toll system with a "triple-step" toll system. Similar calculations used to obtain the previous function (Low Toll (LT)) are now used to calculate the new function named High Toll (HT) and to obtain the savings from the double versus triple step toll system. 
The Function High Toll (HT) can be obtained using Equation (3.8) and (3.19):

Function High Toll $(\mathrm{HT})=\operatorname{sravc}(q)+T_{H i g h}$

Using equation (3.8) and (3.20) we have:

Function High Toll $(\mathrm{HT})=\tau+\frac{\mathrm{v}}{(V-\delta q)}+T_{H i g h}$

Similar calculations can be used to obtain functions for "n-step" toll systems and use these functions to compare the savings between different tolls in a "multiple-step" toll system.

3.2.7 Step 7.- Savings from imposing the Double-Step Toll or High Demand Toll.- If the high demand toll is not imposed the welfare loss of not imposing the marginal cost pricing will be equal to the dashed area in Figure 3.4. Once the high demand toll is imposed, this welfare loss can be transformed into savings for the system or savings from the double-step toll equal to the same dashed area.

Using equation (3.2) it is possible to obtain the savings from imposing a toll for a high demand situation as follows:

$\mathrm{S}_{D S}=S_{S S}+\sum_{q=q_{b}}^{q_{c}} \operatorname{srmc}(p)-\sum_{q=q_{b}}^{q_{c}} m b_{H}(p)$

Using Equation (3.6), (3.12) and (3.18) we have:

$\mathrm{S}_{D S}=\left(\sum_{q=q_{0}}^{q_{a}}\left(\tau+\frac{v V}{(V-\delta q)^{2}}\right)-\sum_{q=q_{0}}^{q_{a}}\left(\frac{\boldsymbol{\alpha}_{L}}{\boldsymbol{\beta}_{L}}-\frac{q}{\boldsymbol{\beta}_{L}}\right)\right)+\left(\sum_{q=q_{b}}^{q_{c}}\left(\tau+\frac{v V}{(V-\delta q)^{2}}\right)-\sum_{q=q_{b}}^{q_{c}}\left(\frac{\boldsymbol{\alpha}_{H}}{\boldsymbol{\beta}_{H}}-\frac{q}{\boldsymbol{\beta}_{H}}\right)\right)$

Again, is important to note that if the savings from imposing a double-step toll are lower than the costs of implementing and operating the system, then the double-step toll system is not economically efficient and it is necessary to explore new pricing alternatives.

3.2.8 Step 8.- Comparison of the Single-Step Toll System and the Double-Step Toll System using the savings and the function (LT).- Once the savings from the single and double-step toll system have been calculated it is necessary to compare them. This comparison is a good analysis tool to value the implementation of a double-step toll system versus a single-step toll system. 


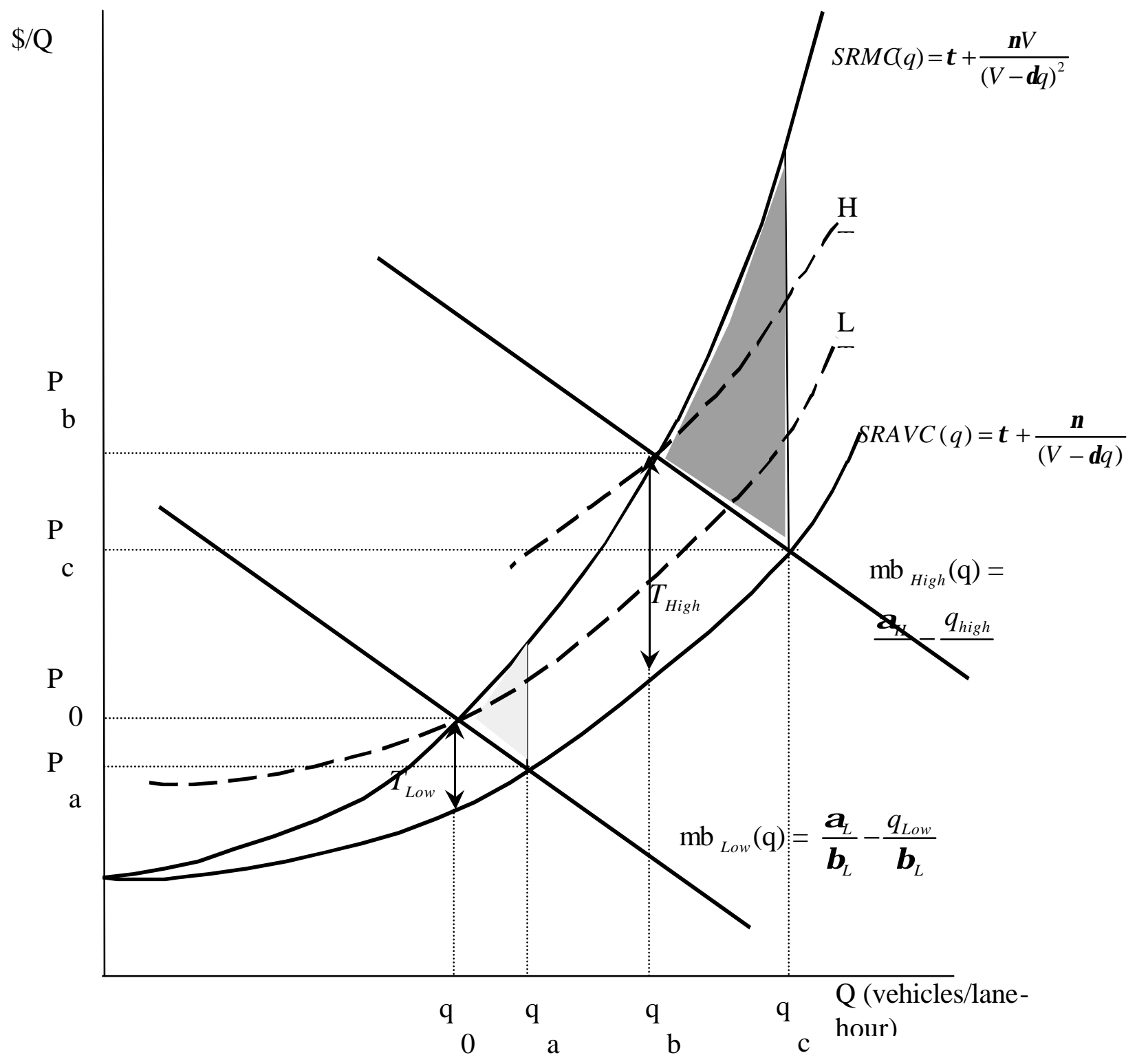

Figure 3.4. Single and Double step toll systems savings and functions

If the savings between a single and double-step toll system are greater than the costs of implementation and operation of the double-step toll system, then the double-step toll system may be is preferred to a single-step toll system. On the other hand, if the savings between the single and double-step toll system are lower than the implementation and operation costs of a double-step toll system, then the single-step toll system is the preferred system. 
As mentioned earlier in this chapter, the Function Low Toll (LT) previously calculated is one of the tools used to reflect the savings of the single-step toll system into the double-step toll system.

Deducting the savings from the single-step toll system from the savings of the doublestep toll system, using the Function Low is the way to obtain and compare the savings from these two systems. Using Figure 3.5 it is possible to observe that the Function (LT) reflect the savings of the single-step toll system (dotted area) into the savings of the double-step toll system (ABC area).

If we deduct the single-step toll system savings from the double-step toll system savings, the result will be the savings from imposing a double-step toll system versus a single-step toll system (dashed area, Figure 3.5).

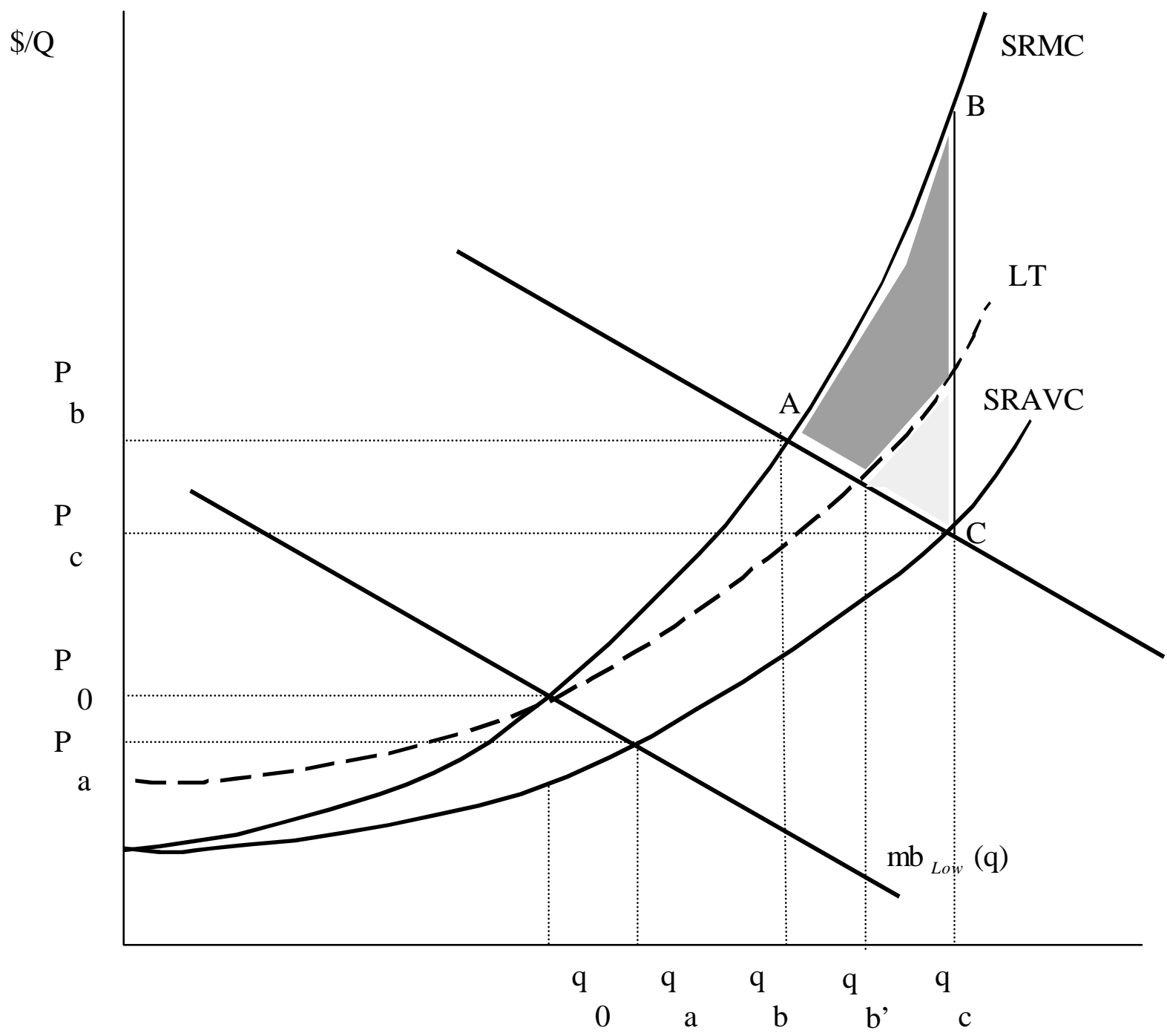

Fig. 3.5 Comparison of the savings between a single and a double step toll system 
Deducting from the double-step toll system savings the savings from the single step toll system reflected into the savings of the double step toll system using Function (LT) we have:

$\mathrm{S}_{D v s S}=\left(\mathrm{S}_{S S}+\mathrm{S}_{D S}\right)-\left(\sum_{q=q_{b^{\prime}}}^{q_{c}}(F L)-\sum_{q=q_{b^{\prime}}}^{q_{c}} m b_{H i g h}(p)\right)$

Substituting Equation (3.5), (3.15) and (3.23) into equation (3.24) we have:

$S_{D v s S}=\left(S_{S S}+\sum_{q=q_{b}}^{q_{c}}\left(\tau+\frac{v V}{(V-\delta q)^{2}}\right)-\sum_{q=q_{b}}^{q_{c}}\left(\frac{\boldsymbol{\alpha}_{L}}{\boldsymbol{\beta}_{L}}-\frac{q}{\boldsymbol{\beta}_{L}}\right)\right)-\left(\sum_{q=q_{b^{\prime}}}^{q_{c}}\left(\tau+\frac{\boldsymbol{v}}{(V-\delta q)}+T_{L o w}\right)-\sum_{q=q_{b^{\prime}}}^{q_{c}}\left(\frac{\boldsymbol{\alpha}_{H}}{\boldsymbol{\beta}_{H}}-\frac{q}{\boldsymbol{\beta}_{H}}\right)\right)$

Where $S_{D v s}$ are the savings of the double-step toll system versus the single-step toll system

In a similar way, the savings used to compare multiple-step toll system can be calculated, using the savings from the $n$-step toll system less the reflected value of the savings from the $n-1$ step toll system using the function $\mathrm{n}-1\left(\mathrm{~F}_{n-1}\right)$, as follows:

$\mathrm{S}_{n}=\sum_{q=q_{x}}^{q_{y}} \operatorname{SRMC}(p)-\sum_{q=q_{x}}^{q_{y}} m b_{x}(q)$

Where $\mathrm{S}_{n}$ are the savings from the $\mathrm{n}$-step toll system, $\mathrm{q}_{x}$ and $\mathrm{q}_{y}$ are the starting and ending volumes in which the $\mathrm{n}$-step toll system is applied and $\mathrm{mb}_{x}(\mathrm{q})$ are the marginal benefits for an $\mathrm{x}$ demand conditions.

$\mathrm{F}_{n-1}=\operatorname{sravc}(\mathrm{q})-T_{n-1}$

Where $\mathrm{F}_{n-1}$ is the function calculated from the conditions of the $n-1$ step toll system and $T_{n-1}$ is the toll applied in the $\mathrm{n}-1$ step toll system.

Using equation (3.20) and (3.21) we are able to calculate the difference in savings between the $\mathrm{n}$ and the $\mathrm{n}-1$ step toll system:

$\mathrm{S}_{M S}=\left(\mathrm{S}_{n}\right)-\left(\sum_{q=q_{x^{\prime}}}^{q_{x^{\prime}+y}}\left(F_{n-1}\right)-\sum_{q=q_{x^{\prime}}}^{q_{x^{\prime}+y}} m b_{x}(q)\right)$

Where $\mathrm{S}_{M S}$ are the savings of the $\mathrm{n}$-step toll system versus the $\mathrm{n}-1$ step toll system, $\mathbf{q}_{x^{\prime}}$ and $\mathrm{q}_{x^{\prime}+y}$ is the starting and ending point from where the savings of the $n-1$ step toll system are reflected into the savings of the $n$-step toll system. 


\subsection{Summary}

Applying all the steps from this model it is possible to obtain the savings from a single and a double step toll system and then compare this savings to check if is economically possible to implement a double-step toll system instead of a single-step toll system.

The costs of implementation and operation of the toll system should be lower than the savings obtained from the tolling system. This rule applied also in the implementation of the double-step toll system, if the savings between a double-step toll system versus the single step toll system are higher than the costs of implementing and operating the double-step toll system, this system will be preferred than the single-step toll system.

Also, in the methodology, was mentioned the way to calculate the savings and their comparison in a multiple-step toll system.

The comparison study of the savings in a multiple-step toll system is an excellent tool to

analyze the accuracy and efficiency of the multiple-step toll systems from an economical point of view. 


\section{Chapter 4. CASE STUDIES}

\subsection{Introduction}

It is necessary to demonstrate the methodology employed in this research work with an experiment involving practical case studies. Case studies illustrate how to obtain the savings from the single and double-step tolls and then uses the results to choose the most economical efficient toll system.

The discussion in this chapter pertains not only to obtaining the savings from both toll systems but also to obtaining the different cost functions related to the congestion pricing mechanism.

The first step is to obtain a set of demand functions related to low and high demand cases. Next, it is necessary to obtain the cost functions related to the operation of the vehicle ( $\operatorname{sravc}$ ) and the extra cost imposed by any extra car on the facility $(s r m c)$. Finally, the savings from the single and the double-step toll system are calculated and with the help of the low toll function that relates the savings from the single-step to the savings of the double-step to obtain the savings between a single and a double-step toll system.

The results obtained using this methodology should be a good analytical tool to use in an economic evaluation of the single and double-step toll systems and going one step further can be use to evaluate the economic efficiency of a multiple-step toll system.

\subsection{Problem Statement}

Today there is not any toll road or transportation facility that operates in a "pure" marginal cost scheme so the different scenarios or case studies presented here are based on hypothetical cases using estimated data of the volumes, speeds and speed reduction parameters. The intent is to explore the amount of savings associated with two-stepped tolls over a range of explanatory variables. The variables fall into the general category of facility variables, operational variables and exogenous variables.

Basically, two different experiments with the four different scenarios described in Chapter 3 were run using the model proposed in this research work. The experiments proposed are described below, in each case an assumption of having only cars and no trucks on the systems is made, also it is considered that the conditions of the demand are price inelastic:

1. Peak Versus Off-peak periods in an urban road. Using the data available for a one mile trip on a two lane urban road and the model proposed here, it is possible to calculate the different cost functions and demand functions required to obtain the savings between a peak period ("high" demand case) and an off-peak period ("low" demand case). A toll for a case of low demand will be charged during the off-peak period and a toll for a high demand case will be charged during the peak period. The savings for imposing a double- 
step toll will be compared with the savings of imposing just one toll regardless the time of the day.

2. Peak Versus Off-peak periods in a highway. Using the data available for a highway and the model proposed here, it is possible to calculate the savings between the peak and the off- peak period for a one-mile trip on a two lane high volume highway. A toll for a case of low demand will be charged during the off-peak period and a toll for a high demand case will be charged during the peak period. The savings for imposing a double-step toll will be compared with the savings of imposing just one toll regardless of the time of the day.

\subsection{Data}

The next table indicates the data used in each one of the experiments.

Table 4.1 Baseline data used in the experiments

\begin{tabular}{|l|c|c|c|c|}
\hline $\begin{array}{c}\text { Experiment } \\
\text { Number }\end{array}$ & $\begin{array}{c}\tau \\
\text { Vehicle } \\
\text { Fixed } \\
\text { Costs }\end{array}$ & $\begin{array}{c}\mathrm{V} \\
\mathrm{Mph} \\
\text { Free Flow } \\
\text { Speed }\end{array}$ & $\begin{array}{c}\boldsymbol{\delta} \\
\text { Speed } \\
\text { Reduction } \\
\text { Parameter }\end{array}$ & $\begin{array}{c}\mathrm{v} \\
\text { Travel } \\
\text { Time Value } \\
\text { cents/veh/hr }\end{array}$ \\
\hline $\begin{array}{l}\text { 1. Peak Vs } \\
\text { Off-Peak, } \\
\text { Urban road }\end{array}$ & 39.65 & 28 & 0.008 & 1650 \\
\hline $\begin{array}{l}\text { 2. Peak Vs } \\
\text { Off-peak, } \\
\text { Highway }\end{array}$ & 39.65 & 65 & 0.003 & 1650 \\
\hline
\end{tabular}

An example of the calculations using the Ordinary Least Squares method of the low demand curve and high demand curve are shown in Appendix A.

For the variation on the value of travel time scenario, it is necessary to change the value of travel time. The range of travel time values for each running of this scenario is 500, 1000, 1500, 2000, and 2500 cents per vehicle hour.

The volumes or flow rates used in each one of the experiments are shown in the next table, we assume that the volume/capacity ratio for each facility is higher than 0.4 in order to have a congested facility where congestion pricing is justified. 
Table 4.2 Flow rate or Volumes for each experiment

\begin{tabular}{|c|c|}
\hline $\begin{array}{c}\text { Experiment 1 } \\
\text { Vehicles/hour }\end{array}$ & $\begin{array}{c}\text { Experiment 2 } \\
\text { Vehicles/hour }\end{array}$ \\
\hline 0 & 0 \\
1200 & 500 \\
1300 & 1000 \\
1400 & 1500 \\
1500 & 2000 \\
1600 & 2500 \\
1700 & 3000 \\
1800 & 3500 \\
1900 & 4000 \\
2000 & 4500 \\
2100 & 5000 \\
\hline
\end{tabular}

Using the previous data and equations (3.8) and (3.11) from Chapter 3 we obtain the general formula to calculate the short run average variable cost $(\operatorname{sravc})$ and the short run marginal cost (srmc):

Table 4.3 Short run average variable cost General Equations

\begin{tabular}{|c|c|}
\hline Experiment Number & $\begin{array}{c}\text { short run average variable cost } \\
(\text { (sravc) }\end{array}$ \\
\hline 1 & $\operatorname{sravc}(q)=37.41+\frac{1094}{(28-0.008 q)}$ \\
\hline 2 & $\operatorname{sravc}(q)=37.41+\frac{1094}{(65-0.005 q)}$ \\
\hline
\end{tabular}

Table 4.4 Short run marginal cost General Equations

\begin{tabular}{|c|c|}
\hline Experiment Number & short run marginal cost (srmc) \\
\hline 1 & $\operatorname{srmc}(q)=37.41+\frac{1094 * 28}{(28-0.008 q)^{2}}$ \\
\hline 2 & $\operatorname{srmc}(q)=37.41+\frac{1094 * 65}{(65-0.005 q)^{2}}$ \\
\hline
\end{tabular}

With the data from tables 4.1, 4.2, 4.3 and 4.4 it is possible now to obtain the calculations for the different experiments and scenarios. 


\subsection{Calculations}

4.4.1 Single step toll and calculation of the function Low Toll (LT). According to Figure 3.4 the value of the volume q necessary to obtain the single toll will be the volume equal to $q_{o}$. The curve $\mathrm{mb}_{L}(\mathrm{q})$ intersects the curve srmc (q) at a volume of $q_{o}$. With this volume and Equation (3.13) from Chapter 3 we have the following equations for the single toll in each experiment and scenario:

Table 4.5 Single-step Toll General Equations

\begin{tabular}{|c|c|}
\hline Experiment Number & Equations for the Single-Step Toll \\
\hline 1 & $T_{\text {Low }}=\frac{1094^{*} 0.008 q_{0}}{\left(28-0.008 q_{0}\right)^{2}}$ \\
\hline 2 & $T_{\text {Low }}=\frac{1094^{*} 0.005 q_{0}}{\left(65-0.008 q_{0}\right)^{2}}$ \\
\hline
\end{tabular}

We now only need to substitute the values of the different $q_{o}$ volumes and obtain the singlestep toll.

Using Equation (3.15) and the data available, we can obtain the equation for the Function Low Toll (LT) for each one of the experiments and scenarios. With the Function Low Toll it is possible to reflect the savings from the single-step toll into the savings of the double-step toll. The general formula used to obtain the Function Low Toll for each experiment is:

Table 4.6 Low Toll Function General Equations

\begin{tabular}{|c|c|}
\hline Experiment Number & Low Toll Function (LT). General Formula \\
\hline 1 & Low Toll Function (LT) $=37.42+\frac{1094}{(28-0.008 q)}+T_{\text {Low }}$ \\
\hline 2 & Low Toll Function (LT) $=37.42+\frac{1094}{(65-0.005 q)}+T_{\text {Low }}$ \\
\hline
\end{tabular}

4.4.2 Savings from the single step toll system. To obtain the savings from the single toll, first is necessary according to Figure 3.4 to obtain the value of the volume equal to $q_{a}$. The volume where the curve $\operatorname{sravc}(\mathrm{q})$ intersects the curve $\mathrm{mb}_{L}(\mathrm{q})$ is equal to $q_{a}$. Solving equations (3.4) and (3.8), we obtain the value of $q_{a}$ for each experiment. Using Equation 3.17 and the value of $q_{a}$, we have the following general formula to obtain the savings from the single-step toll for each experiment: 
Table 4.7 Single-step Savings General Equations

\begin{tabular}{|c|c|}
\hline Experiment Number & Single-Step Savings. General Formula \\
\hline 1 & $\mathrm{~S}_{s s}=\sum_{q=q_{0}}^{q_{c}}\left(37.41+\frac{1094 * 28}{(28-0.008 q)^{2}}\right)-\sum_{q=q_{0}}^{q_{c}}\left(\frac{\boldsymbol{\alpha}_{L}-q}{\boldsymbol{\beta}_{L}}\right)$ \\
\hline 2 & $\mathrm{~S}_{s s}=\sum_{q=q_{0}}^{q_{c}}\left(37.41+\frac{1094 * 65}{(65-0.005 q)^{2}}\right)-\sum_{q=q_{0}}^{q_{c}}\left(\frac{\boldsymbol{\alpha}_{L}-q}{\boldsymbol{\beta}_{L}}\right)$ \\
\hline
\end{tabular}

4.4.3 Double-step toll and calculation of the function for the double-step toll (HT). In Figure 3.4 the value of the volume q necessary to obtain the double-step toll will be the volume equal to $q_{b}$. The curve $\mathrm{mb}_{H}(\mathrm{q})$ intersects the curve srmc (q) at a volume of $q_{b}$. Using the previous data, equating equation (3.6) and (3.11) and solving, we obtain the value of $q_{b}$ for each experiment. Using the previous data, the volume $q_{b}$ and the equation (3.19) from Chapter 3 we have the following general equation for the double toll in each experiment:

Table 4.8 Double-step Toll General Equations

\begin{tabular}{|c|c|}
\hline Experiment Number & $\begin{array}{c}\text { Equations for the Double-Step Toll. } \\
\text { General formula }\end{array}$ \\
\hline 1 & $T_{H i g h}=\frac{1094 * 0.008 q_{b}}{\left(28-0.008 q_{b}\right)^{2}}$ \\
\hline 2 & $T_{H i g h}=\frac{1094 * 0.005 q_{b}}{\left(65-0.005 q_{b}\right)^{2}}$ \\
\hline
\end{tabular}

With equation 3.21 from Chapter 3 and the data available, we obtain the following equation for the Function High Toll (HT) for each one of the experiments:

Table 4.9 High Toll Function General Equations

\begin{tabular}{|c|c|}
\hline Experiment Number & $\begin{array}{l}\text { High Toll Function (HT). General } \\
\text { Formula }\end{array}$ \\
\hline 1 & $6.2+\left(\frac{1094}{(28-0.008 q)}\right)+T_{H i g h}$ \\
\hline 2 & $6.2+\left(\frac{1094}{(65-0.005 q)}\right)+T_{H i g h}$ \\
\hline
\end{tabular}

4.4.4 Savings from the double-step toll system. To obtain the savings from the double-step toll, first it is necessary to obtain the value of the volume equal to $q_{c}$, Figure 3.4. The volume where 
the curve $\operatorname{sravc}(\mathrm{q})$ intersects the curve $\mathrm{mb}_{H}(\mathrm{q})$ is equal to $q_{c}$. Solving equations (3.6) and (3.8) we obtain the value of $q_{c}$ for each experiment. Using equation (3.23) from chapter 3 and the previous data we have the following general equations to obtain the savings from the double-step toll for each experiment:

Table 4.10 Double-Step Savings General Formula

\begin{tabular}{|c|c|}
\hline Experiment Number & Double-Step Savings. General Formula \\
\hline 1 & $\mathrm{~S}_{D S}=\mathrm{S}_{S S}+\left(\sum_{q=q_{b}}^{q_{c}}\left(37.41+\frac{1094 * 28}{(28-0.008 q)^{2}}\right)-\sum_{q=q_{b}}^{q_{c}}\left(\frac{\boldsymbol{\alpha}_{H}}{\boldsymbol{\beta}_{H}}-\frac{q}{\boldsymbol{\beta}_{H}}\right)\right)$ \\
\hline 2 & $\mathrm{~S}_{D S}=\mathrm{S}_{S S}+\left(\sum_{q=q_{b}}^{q_{c}}\left(37.41+\frac{1094 * 65}{(65-0.005 q)^{2}}\right)-\sum_{q=q_{b}}^{q_{c}}\left(\frac{\boldsymbol{\alpha}_{H}}{\boldsymbol{\beta}_{H}}-\frac{q}{\boldsymbol{\beta}_{H}}\right)\right)$ \\
\hline
\end{tabular}

4.4.5 Comparison of the savings between a single and a double-step toll system. Once the savings from the single and a double step toll systems has been obtained, the final step is compare these savings using the function for a low toll (LT) obtained previously and equation (3.23) from Chapter 3. In order to obtain the results, we need the value of the volume $q_{b}$, where the Function Low Toll (LT) curve intersects the Demand High curve.

Solving equation (3.6) and the equations for the Function Low Toll (LT) we obtain the value of $q_{b^{\prime}}$ for each experiment. Using equation (3.25) and the previous data we have the following general formula to obtain the savings between the single and the double-step toll for each experiment:

Table 4.11 Single versus Double-step savings General Equations

\begin{tabular}{|c|c|}
\hline Experiment Number & Double-Step Savings. General Formula \\
\hline 1 & $\mathrm{~S}_{D S}=\mathrm{S}_{S S}+\left(\sum_{q=q_{b}}^{q_{c}}\left(37.41+\frac{1094 * 28}{(28-0.008 q)^{2}}\right)-\sum_{q=q_{b}}^{q_{c}}\left(\frac{\boldsymbol{\alpha}_{H}}{\boldsymbol{\beta}_{H}}-\frac{q}{\boldsymbol{\beta}_{H}}\right)\right)$ \\
\hline 2 & $\mathrm{~S}_{D S}=\mathrm{S}_{S S}+\left(\sum_{q=q_{b}}^{q_{c}}\left(37.41+\frac{1094 * 65}{(65-0.005 q)^{2}}\right)-\sum_{q=q_{b}}^{q_{c}}\left(\frac{\boldsymbol{\alpha}_{H}}{\boldsymbol{\beta}_{H}}-\frac{q}{\boldsymbol{\beta}_{H}}\right)\right)$ \\
\hline
\end{tabular}

\subsection{Output}

Using a spreadsheet and the data obtained here it is possible to obtain the results from the different experiments by applying the model. The final results obtained from the calculations are shown in Table 4.12. Planners and decision makers may use the analysis of the different tolling alternatives presented in Table 4.12 along with implementation and operation costs as a tool to compare savings of the different tolling systems and obtain the one with the better economic efficiency.

The best tolling system will be the one that at least bears the implementation and operation costs and in the best case report revenues. 
The most important benefit of imposing a toll system is the removal of congestion present in the road. As mentioned in Chapter 2, if a single toll is imposed the amount of queue removed will be equal to $q_{a}-q_{0}$ vehicles per hour and if a double step toll is imposed the amount of queue removed will be equal to $\left(q_{a}-q_{0}\right)+\left(q_{c}-q_{b}\right)$ vehicles per hour. Also Table 4.12 summarizes the amount of queue removed by each tolling system under the different scenarios.

Table 4.12 Savings, Queue removed and Tolls

\begin{tabular}{|c|c|c|c|c|c|c|c|c|}
\hline & & \multirow{2}{*}{\multicolumn{3}{|c|}{ SAVINGS }} & \multirow{2}{*}{\multicolumn{2}{|c|}{ QUEUE REMOVED }} & \multirow{4}{*}{$\begin{array}{l}\text { Toll } \\
\text { Low } \\
\text { (cents) }\end{array}$} & \multirow{4}{*}{$\begin{array}{c}\text { Toll } \\
\text { High } \\
\text { (cents) } \\
\end{array}$} \\
\hline & & & & & & & \\
\hline & & \multirow{2}{*}{$\begin{array}{l}\text { Single } \\
\text { Step } \\
\text { (cents) }\end{array}$} & \multirow{2}{*}{$\begin{array}{l}\text { Double } \\
\text { Step } \\
\text { (cents) }\end{array}$} & \multirow{2}{*}{$\begin{array}{c}\text { Single Vs Double } \\
\text { Step } \\
\text { (cents) }\end{array}$} & \multirow{2}{*}{$\begin{array}{c}\text { Single } \\
\text { Step } \\
\text { (veh/hour) }\end{array}$} & \multirow{2}{*}{$\begin{array}{c}\text { Double } \\
\text { Step } \\
\text { (veh/hour) }\end{array}$} & & \\
\hline EXPERIMENT & CONDITIONS & & & & & & & \\
\hline \multirow{19}{*}{$\begin{array}{l}\text { 1. Peak and Off-peak period } \\
\text { Urban Road }\end{array}$} & HD set, LD increasing & 138.81 & 1252.89 & 1237 & 244 & 392 & 76 & 199 \\
\hline & HD set, LD increasing & 161.07 & 1275.15 & 1220.91 & 239 & 387 & 88 & 199 \\
\hline & HD set, LD increasing & 172.02 & 1220.38 & 1194.64 & 238 & 386 & 94 & 199 \\
\hline & HD set, LD increasing & 208.33 & 1220.35 & 1155.94 & 224 & 372 & 114 & 199 \\
\hline & HD set, LD increasing & 336.74 & 1240.5 & 1032.95 & 161 & 309 & 185 & 199 \\
\hline & LD set, HD increasing & 94.18 & 263.46 & 292.89 & 245 & 492 & 52 & 59 \\
\hline & LD set, HD increasing & 94.18 & 335.63 & 362.89 & 245 & 493 & 52 & 68 \\
\hline & LD set, HD increasing & 94.18 & 546.76 & 566.75 & 245 & 483 & 52 & 94 \\
\hline & LD set, HD increasing & 94.18 & 941.24 & 943.97 & 245 & 438 & 52 & 145 \\
\hline & LD set, $H D$ increasing & 94.18 & 1340.99 & 1303.04 & 245 & 393 & 52 & 199 \\
\hline & EpLD>1 EpHD>1 & 159.11 & 805.23 & 896.32 & 533 & 1141 & 60 & 93 \\
\hline & EpLD $<1 \quad$ EpHD $>1$ & 86.07 & 943.68 & 978.59 & 430 & 1038 & 42 & 93 \\
\hline & $E p L D>1 \quad$ EpHD $<1$ & 159.11 & 188.04 & 283 & 533 & 867 & 60 & 48 \\
\hline & EpLD $<1 \quad$ EpHD $<1$ & 96.29 & 530.37 & 570.01 & 334 & 822 & 48 & 76 \\
\hline & Varying Travel Time Value & 59.24 & 547.54 & 501.21 & 179 & 244 & 33 & 83 \\
\hline & Varying Travel Time Value & 81.69 & 915.37 & 877.72 & 226 & 335 & 45 & 142 \\
\hline & Varying Travel Time Value & 92.66 & 1246.05 & 1208.92 & 243 & 383 & 51 & 187 \\
\hline & Varying Travel Time Value & 85.59 & 1535.16 & 1488.34 & 254 & 417 & 52 & 224 \\
\hline & Varying Travel Time Value & 49.7 & 1769 & 1688.02 & 279 & 462 & 50 & 254 \\
\hline \multirow{19}{*}{$\begin{array}{l}\text { 2. Peak and Off-peak period } \\
\text { Highway }\end{array}$} & HD set, LD increasing & 2.92 & 58.18 & 59.26 & 218 & 1120 & 2 & 10 \\
\hline & HD set, LD increasing & 5.95 & 50.56 & 51.66 & 502 & 1404 & 4 & 10 \\
\hline & HD set, LD increasing & 6.91 & 47.83 & 49.15 & 586 & 1488 & 5 & 10 \\
\hline & HD set, LD increasing & 9.19 & 41.87 & 43.8 & 784 & 1686 & 7 & 10 \\
\hline & HD set, LD increasing & 13.47 & 31.92 & 35.28 & 1044 & 1946 & 9 & 10 \\
\hline & LD set, HD increasing & 4.76 & 16.19 & 12.98 & 248 & 544 & 3 & 4 \\
\hline & LD set, HD increasing & 4.76 & 18.79 & 19.38 & 248 & 671 & 3 & . \\
\hline & LD set, HD increasing & 4.76 & 29.65 & 30.53 & 248 & 860 & 3 & 7 \\
\hline & LD set, $H D$ increasing & 4.76 & 53.46 & 53.91 & 248 & 1187 & 3 & 10 \\
\hline & LD set, HD increasing & 4.76 & 78.29 & 78.97 & 248 & 1476 & 3 & 13 \\
\hline & EpLD>1 EpHD>1 & 10.95 & 34.52 & 36.93 & 762 & 1701 & 8 & 10 \\
\hline & EpLD $<1 \quad$ EpHD $>1$ & 6.78 & 48.02 & 49.23 & 423 & 1362 & 5 & 10 \\
\hline & EpLD $>1 \quad$ EpHD $<1$ & 19.24 & -17.67 & -12.13 & 1228 & 1476 & 13 & \\
\hline & EpLD $<1 \quad$ EpHD $<1$ & 4.76 & 18.79 & 19.38 & 248 & 671 & 3 & 5 \\
\hline & Varying Travel Time Value & 2.95 & 26.95 & 27.04 & 154 & 735 & 2 & 6 \\
\hline & Varying Travel Time Value & 4.19 & 36.37 & 36.89 & 227 & 986 & 3 & 8 \\
\hline & Varying Travel Time Value & 4.93 & 40.07 & 40.97 & 245 & 1014 & 4 & 10 \\
\hline & Varying Travel Time Value & 4.78 & 40.28 & 41.04 & 233 & 957 & 4 & 10 \\
\hline & Varying Travel Time Value & 4.45 & 38.01 & 39.03 & 191 & 840 & 3 & \\
\hline
\end{tabular}




\subsection{Discussion of Results}

From the results presented on Table 4.12 is possible to observe the following:

- If both low and high demand curves increase the savings from the single step, double step and the single versus double step will increase.

- If the high demand is set and the low demand is increasing the savings from the single step toll will increase but the savings from the double step toll will decrease. This is because the low demand curve is approaching the conditions of the high demand curve until become very similar. In this case a double step toll system is preferred than a single step toll system only when both demand curves are well separated and their conditions are not similar.

- It is considered that the demand for travel should be price inelastic, however the model gives results using price elastic demands of the savings. In this case the savings from a price elastic demand are higher than the price inelastic but a price elastic situation will be very difficult to occur.

- On a single step toll, varying the value of travel time will increase the savings until a value of travel time not higher than 1900 cents per vehicle hour. Values higher than 1900 cents per vehicle hour will decrease the savings from a single step toll.

- A double step toll can reflect better the changes on the value of travel time. Higher values of travel time will generate higher savings from the double step toll system, also the savings between a single and a double step toll system will be higher. If there are variations on the value of travel time on the system, a double step toll system will be preferred than a single step toll system.

- In the case of the tolls charged and the amount of congestion removed when a toll system is applied on an urban road, the tolls for the single and double step toll systems are reasonable. It is possible to observe that the double step toll is usually around two times the single step toll. The amount of congestion removed will depend on the conditions of the demand but certainly a double step toll system can remove more than double of congestion than the single step toll.

- In the case of the tolls charged and the amount of congestion removed when a toll system is applied on a highway, the tolls for the single and double step toll systems are lower than in an urban road. This is because the conditions of the demand due to higher volumes. It is possible to observe that the double step toll is usually more than two times the single step toll. In this case the single toll is very low with values not reasonable to charge, even the values of the double step bll are very low. Even with very low tolls, the amount of congestion removed will be higher than in an urban road and in this case a double step toll system can remove around three times more congestion than the single step toll. 


\subsection{Conclusions}

The model follows the closest marginal cost pricing scheme possible, which make it more approximate to an ideal economic model. Once we have the demand and cost functions for certain road the calculations to obtain the savings from both the single and double-step toll system are quite easy. As mention at the beginning of this chapter, these results are based on hypothetical example cases, the methodology should work well in a actual cases, however care must be taken in obtaining values for the required inputs.

Beyond the calculations of the savings of each tolling system, the model can calculate also the amount of queue removed by each tolling system. This is another useful tool to evaluate each system from an operational point of view. 


\section{Chapter 5. CONCLUSIONS}

The method used to compare the savings between a single and a double step tolling systems is a valuable and useful tool in an economical analysis. Usually all the important decisions are based ultimately in the monetary savings and the tolling systems are not the exception.

In this research work it was employed a method that can be applied to different tolling systems in different project stages even to a system already in operation. The method is very flexible and can go beyond a double-step tolling system to a multiple-step tolling system.

A time-varying tolling system is the most economical efficient and close to the reality but difficult to implement. A multiple-step toll system is the closest to a time-varying system, is also easily to implement and understand by the users.

The single-step toll system produces savings depending on volume and demand of more than 300 cents per vehicle-hour in the case of an urban road and more than 13 cents per vehiclehour in a highway. Also removes up to $1 / 3$ of the congestion that exists under the non-toll equilibrium. A single-step toll it easily to implement and operate but it only feasible under low volume conditions.

A double-step toll system can generate savings depending on the volume and demand of more than 1500 cents per vehicle-hour, 5 times more than the single-step tolling system in the case of an urban road. In a highway, a double-step toll system can generate savings depending on the volume and demand of more than 78 cents per vehicle-hour, 6 times more than the singlestep tolling system. Also it can remove up to $2 / 3$ of the congestion that exists under the non-toll equilibrium, 1/3 more than the single-step toll system. A double-step toll system is also easily to implement and operate but is only economically feasible under high volume conditions.

Beyond a double-step tolling system, some researchers conclude that a triple-step toll system can remove $1 / 4$ more queuing than the single step toll systems but they fail to mention the amount of savings generated, using this method is possible to obtain them.

The data used in this method is based on theory. However the results are accurate and close to real situations. In the near future will be able to observe roads that operate in a marginal cost scheme, the technology necessary to implement it is already available and a great amount of research in this field has been done. This research work is another contribution to the congestion pricing area. Future research into the implementation and operation costs especially with the new technology available, value of travel time and demand functions will provide additional data necessary to produce an accurate economical analysis of the different tolling systems. 


\section{REFERENCES}

American Automobile Association. "Your Driving Costs". Annual Issue. Heathrow, Fl. 1998.

Arnott, R, de Palma, A. "Departure Time and Route Choice for the Morning Commute" Transportation Research B, Vol. 24B No. 3._Great Britain 1990, pp 209-228.

Chui, MK, McFarland, WF. "The Value of Travel Time: New Estimates Developed Using a Speed-Choice Model. Final Report." FHWA Report. Report No. FHWA/TX-86/33+396-2F May 1986, Washington D.C.

Downs, A. Struck in Traffic: Coping with Peak-Hour Traffic Congestion. Brookings Institution. Washington D.C. 1992

Dupuit, J. "On Tolls and Transportation Charges". Reprinted in International Economy Papers. New York 1962. pp 7-31.

Ellet, C. "A popular exposition of the incorrectness of the tariffs on tolls in use on the public improvements of the United States". J. Franklin Institute 29. New York_1840, 225-232.

Federal Reserve Bank. Cost Price Index (CPI). Monthly Publication. Washington D.C 2000.

Gomez-Ibanez, J. "The Political Economy of Highway Tolls and Congestion Pricing” Journal of Transportation Economics and Policy. Vol 46 No. 3, July 1992, New York. pp 343-360.

Guiliano, G. "Equity and Fairness Considerations of Congestion Pricing." Curbing Gridlock Peak-Period Fees To Relieve Traffic Congestion Vol. 2. Transportation Research Board, 1994, Washington D.C. pp 250-279

Haight, F.A. Mathematical Theories of Traffic Flow. Academic Press, 1963 New York.

Higgins Thomas. "Roadpricing: A Clash of Analysis and Politics". Policy Analysis. Vol 7 No. 1. Winter 1981.

Higgins Thomas. "Road Pricing Attempts in the United States". Transportation Research Vol 20 A No. 3. 1986 Great Britain.

Kanafani, A. Transportation Demand Analysis. 1982

Knight, F.H. "Some Fallacies in the Interpretation of the Social Cost". Quarterly Journal of Economy. Vol. 38, 1924, Great Britain. pp 582-606.

Laih, C. "Queuing at a Bottleneck with Single and Multiple-Step Tolls". Transportation Research A. Vol. 28A No. 3. 1994 Great Britain. pp 197-208. 
Litman, T. "Using Road Pricing Revenue: Economic Efficiency and Equity Considerations". Transportation Research Record 1558. Transportation Research Board. 1994, Washington D.C. pp 24-28

Pietrzyk, M. "Electronic Toll Collection Systems" Curbing Gridlock Peak-Period Fees To Relieve Traffic Congestion Vol. 2. Transportation Research Board, 1994, Washington D.C. pp 464-501

Pigou, A. The Economics of Welfare. MacMillan, London 1918.

Studenmund, A. Using Econometrics: A Practical Guide. $3^{\text {rd }}$ Edition. Addison-Wesley, 1997.

U.S. DOT. "Implementing Effective Travel Demand Management Measures: Inventory of Measures and Synthesis of Experience". U.S. DOT Final Report. Washington D.C. September 1993.

Walters, A. The Economics of Road User Charges. The John Hopkins Press, Baltimore, 1968.

Wohl, M, Hendrickson, C. Transportation Investment And Pricing Principles. Wiley

Interscience, 1994 


\section{APPENDIX A}

\section{CALCULATION OF THE DEMAND CURVES USING ORDINARY LEAST SQUARES}

\section{ORDINARY LEAST SQUARES REGRESSION METHOD}

This method assume that the true relationship between the expected or average volume of some dependent variable $y$ and the value of the explanatory variable $x$ is linear, considering some random error and unknown parameters. For estimation, we obtain a sample paired observations of the two variables; that is, given the value of the $i$ th observation of the independent variable $\left(x_{i}\right)$, observe the value of the dependent variable $\left(y_{i}\right)$ which accompanies it for the $n$ observations $i=1,2,3 \ldots, n$. This sample of observations is used to estimate the function

$Y_{i}=\hat{\alpha}+\hat{\beta} x_{i}$

Where $Y_{i}$ is an estimated of the true mean value of the dependent variable when the value of the independent variable is $x_{i}$ and $\hat{\alpha}$ and $\hat{\beta}$ are the estimated parameters values.

In essence, ordinary least squares regression assumes that equation (A.1) is an accurate model of the averages values of $y_{i}$. However, a variety of random errors or residual factors affected the observed values of $y_{i}$ so the model is inexact in estimating observed values. This is expressed as a linear error or residual $e_{i}$ which is unobservable; thus:

$Y_{i}=\hat{\alpha}+\hat{\beta} x_{i}+e_{i}$

For this method coefficients are chosen to minimize the sum of the squared differences between the estimated $Y_{i}$ and observed $y_{i}$ values of the dependent variable, which are the residual terms $e_{i}$ in equation (A.2) for each observation. The resulting estimated parameter values are:

$\hat{\alpha}=\bar{y}-\hat{\beta} \bar{x}$

and

$$
\hat{\beta}=\frac{\sum_{i=1}^{n} x_{i} y_{i}-n \bar{x} \bar{y}}{\sum_{i=1}^{n} x_{i}^{2}-n \bar{x}^{2}}
$$

where 
$\bar{x}=\sum_{i=1}^{n} \frac{x_{i}}{n}$

and

$\bar{y}=\sum_{i=1}^{n} \frac{y_{i}}{n}$

Using the previous equations of the ordinary least square method and a programmed spreadsheet it is possible to calculate the demand functions. The next table is an example of the calculations of the demand functions using the programmed spreadsheet:

ORDINARY LEAST

SQUARES

DEMAND LOW

$n=24.00$

\begin{tabular}{|c|c|c|c|c|c|c|}
\hline Trips (q) & Price $(p)$ & $x y$ & $x / \mathbf{n}$ & $y / n$ & $\begin{array}{c}x^{\wedge} 2- \\
n x(\text { avg })^{\wedge} 2 \\
\end{array}$ & 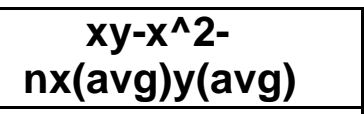 \\
\hline 0.00 & 0.00 & 0.00 & 0.00 & 0.00 & -11466.44 & -3278687.50 \\
\hline 500.00 & 1000.00 & 500000.00 & 41.67 & 20.83 & 988533.56 & -2778687.50 \\
\hline 1000.00 & 50.00 & 50000.00 & 2.08 & 41.67 & -8966.44 & -3228687.50 \\
\hline 1500.00 & 10.00 & 15000.00 & 0.42 & 62.50 & -11366.44 & -3263687.50 \\
\hline 2000.00 & 15.00 & 30000.00 & 0.63 & 83.33 & -11241.44 & -3248687.50 \\
\hline 2500.00 & 9.00 & 22500.00 & 0.38 & 104.17 & -11385.44 & -3256187.50 \\
\hline 3000.00 & 8.00 & 24000.00 & 0.33 & 125.00 & -11402.44 & -3254687.50 \\
\hline 3500.00 & 7.00 & 24500.00 & 0.29 & 145.83 & -11417.44 & -3254187.50 \\
\hline 4000.00 & 6.00 & 24000.00 & 0.25 & 166.67 & -11430.44 & -3254687.50 \\
\hline 4500.00 & 5.00 & 22500.00 & 0.21 & 187.50 & -11441.44 & -3256187.50 \\
\hline 5000.00 & 4.00 & 20000.00 & 0.17 & 208.33 & -11450.44 & -3258687.50 \\
\hline & SUM & 393965 & 21.86 & 6250.00 & 1087918.19 & -85082465.00 \\
\hline
\end{tabular}

$\begin{array}{lr}\text { ALFA LOW } & 7959.43 \\ \text { BETA LOW } & -78.21\end{array}$ 
DEMAND HIGH

\begin{tabular}{|c|c|c|c|c|c|c|}
\hline \multicolumn{7}{|c|}{24.00} \\
\hline Trips (q) & Price (p) & $x y$ & $x / n$ & $y / n$ & $\begin{array}{c}x^{\wedge} 2- \\
n x(\text { avg })^{\wedge} 2\end{array}$ & $\begin{array}{c}\text { xy-x^2- } \\
\text { nx(avg)y(avg) }\end{array}$ \\
\hline 0.00 & 0.00 & 0.00 & 0.00 & 0.00 & -43741.03 & -6403687.50 \\
\hline 500.00 & 1500.00 & 750000.00 & 62.50 & 20.83 & 2206258.97 & -5653687.50 \\
\hline 1000.00 & 50.00 & 50000.00 & 2.08 & 41.67 & -41241.03 & -6353687.50 \\
\hline 1500.00 & 10.00 & 15000.00 & 0.42 & 62.50 & -43641.03 & -6388687.50 \\
\hline 2000.00 & 15.00 & 30000.00 & 0.63 & 83.33 & -43516.03 & -6373687.50 \\
\hline 2500.00 & 9.00 & 22500.00 & 0.38 & 104.17 & -43660.03 & -6381187.50 \\
\hline 3000.00 & 8.00 & 24000.00 & 0.33 & 125.00 & -43677.03 & -6379687.50 \\
\hline 3500.00 & 7.00 & 24500.00 & 0.29 & 145.83 & -43692.03 & -6379187.50 \\
\hline 4000.00 & 6.00 & 24000.00 & 0.25 & 166.67 & -43705.03 & -6379687.50 \\
\hline 4500.00 & 5.00 & 22500.00 & 0.21 & 187.50 & -43716.03 & -6381187.50 \\
\hline 5000.00 & 4.00 & 20000.00 & 0.17 & 208.33 & -43725.03 & -6383687.50 \\
\hline & SUM & & 42.69 & 6250.00 & 1563328.19 & -159832465.00 \\
\hline
\end{tabular}

ALFA 10614.69 HIGH

BETA -102.24

HIGH 


\title{
APPENDIX B
}

\author{
VALUE OF TRAVEL TIME AND FIXED COSTS
}

\section{Cost of Owning and Operating an Automobile $^{\mathrm{a}}$}

\begin{tabular}{|c|c|c|c|c|c|c|c|}
\hline & 1992 & 1993 & 1994 & 1995 & 1996 & 1997 & 1998 \\
\hline $\begin{array}{l}\text { Total cost per mile }{ }^{b, c} \text { (current } \\
\text { Ф) }\end{array}$ & 38.8 & 38.7 & 39.4 & 41.2 & 42.6 & 44.8 & 46.1 \\
\hline Gas and oil & 5.9 & 5.9 & 5.6 & 5.8 & 5.6 & 6.6 & 6.2 \\
\hline $\begin{array}{l}\text { Gas and oil as a \% of total } \\
\text { cost }\end{array}$ & 15.2 & 15.2 & 14.2 & 14.1 & 13.1 & 14.7 & 13.4 \\
\hline Maintenance & 2.2 & 2.4 & 2.5 & 2.6 & 2.8 & 2.8 & 3.1 \\
\hline $\begin{array}{l}\text { Tires } \\
\text { Total cost per } 15,000 \text { miles, }\end{array}$ & 0.9 & 0.9 & 1.0 & 1.2 & 1.2 & 1.4 & 1.4 \\
\hline (Current \$) & 5,824 & 5,804 & 5,916 & 6,185 & 6,389 & 6,723 & 6,908 \\
\hline Variable cost & 1,350 & 1,380 & 1,365 & 1,440 & 1,440 & 1,620 & 1,605 \\
\hline Fixed cost ${ }^{\mathrm{C}}$ & 4,474 & 4,424 & 4,551 & 4,745 & 4,949 & 5,103 & 5,303 \\
\hline \multicolumn{8}{|c|}{$\begin{array}{l}\text { Fixed and total operating costs preceding } 1985 \text { are not comparable to figures after } 1985 \text {. Fixed-cost depreciation from } \\
1975-84 \text { is based on receipt of average trade in value after } 4 \text { years. After 1984, the depreciation is based on } \\
\text { the vehicle's trade in value after } 6 \text { years. }\end{array}$} \\
\hline \multicolumn{8}{|c|}{ C Fixed costs (ownership costs) include: insurance, license, registration, taxes, depreciation, and finance charges. } \\
\hline \multicolumn{8}{|c|}{$\begin{array}{l}\text { and optional accessories. After 1985, the cost figures represent a composite of three current model American cars. } \\
\text { The } 1998 \text { fuel costs are based on an average price of } \$ 1.285 \text { per gallon of regular unleaded gasoline, weighted } 20 \%\end{array}$} \\
\hline \multicolumn{8}{|c|}{$\begin{array}{l}\text { full-serve and } 80 \% \text { self-serve. Insurance figures are based on personal use of vehicles driven less than } 10 \text { miles } \\
\text { to or from work, with no drivers under } 25 \text { years old. Normal depreciation costs are based on the vehicle's trade-in value } \\
\text { at the end of } 4 \text { years or } 60,000 \text { miles. American Automobile Association analysis covers vehicles }\end{array}$} \\
\hline $\begin{array}{l}\text { equipped with standard and optional acces s } \\
\text { steering, power disc brakes, AM/FM stereo, }\end{array}$ & & tom & & & , power & & \\
\hline
\end{tabular}

SOURCE: American Automobile Association, Your Driving Costs (Heathrow, FL: 1998 Annual issue).

Using the value of travel time obtained by Chui and McFarland of \$10.38 (1985 value) cents per vehicle hour, the previous table with the fixed cost data and the annual CPI values is possible to obtain the actual value (2000 value) of the fixed costs and value of travel time for an automobile as follows: 


$\begin{array}{llcr}\text { Year } & \text { CPI } & \text { Value of travel time (cents) } & \text { Fixed Costs (cents) } \\ 1985.00 & 109.30 & 1038.00 & \\ 1986.00 & 110.50 & & \\ 1987.00 & 115.40 & & \\ 1988.00 & 120.50 & & \\ 1989.00 & 126.10 & & \\ 1990.00 & 133.80 & & \\ 1991.00 & 137.90 & & \\ 1992.00 & 141.90 & & \\ 1993.00 & 145.80 & & \\ 1994.00 & 149.70 & & \\ 1995.00 & 153.50 & & \\ 1996.00 & 158.60 & & \\ 1997.00 & 161.30 & & \\ 1998.00 & 163.90 & & \\ 1999.00 & 168.30 & & \\ 2000.00 & 173.70 & & \end{array}$

The CPI annual values were obtained from the Federal Reserve Bank, USA. 


\section{Curriculum Vitae}

\section{Juan Kuthy-Saenger}

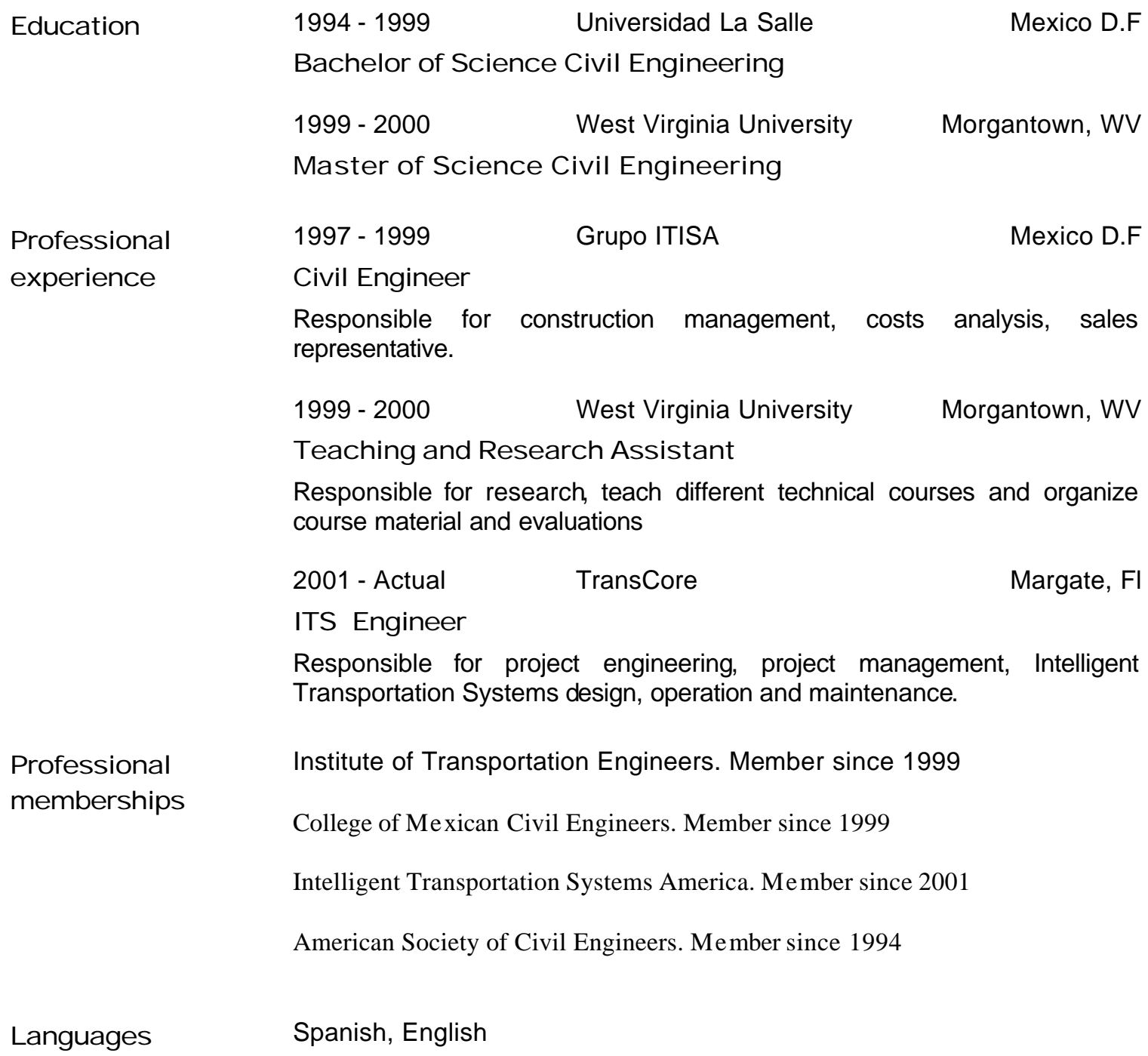

